\title{
Article \\ Cascaded H-Bridge Converter Based on Current-Source Inverter with DC Links Magnetically Coupled to Reduce the DC Inductors Value
}

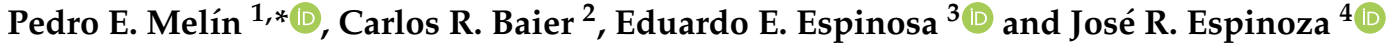 \\ 1 Department of Electrical and Electronic Engineering, Universidad del Bío-Bío, Concepción 4051381, Chile \\ 2 Department of Electrical Engineering, Universidad de Talca, Curicó 3340000, Chile; cbaier@utalca.cl \\ 3 Department of Electrical Engineering, Faculty of Engineering, Universidad Católica de la Santísima \\ Concepción, Concepción 4090541, Chile; eespinosa@ucsc.cl \\ 4 Department of Electrical Engineering, Universidad de Concepción, Concepción 4070386, Chile; \\ jose.espinoza@udec.cl \\ * Correspondence: pemelin@ubiobio.cl; Tel.: +56-41-311-1012
}

\section{check for}

updates

Citation: Melín, P.E.; Baier, C.R.;

Espinosa, E.E.; Espinoza, J.R.

Cascaded H-Bridge Converter Based on Current-Source Inverter with DC Links Magnetically Coupled to Reduce the DC Inductors Value. Energies 2022, 15, 324. https:// doi.org/10.3390/en15010324

Academic Editors: José Gabriel Oliveira Pinto, Fabio Immovilli and Emilio Lorenzani

Received: 18 October 2021

Accepted: 12 December 2021

Published: 4 January 2022

Publisher's Note: MDPI stays neutral with regard to jurisdictional claims in published maps and institutional affiliations.

Copyright: () 2022 by the authors Licensee MDPI, Basel, Switzerland. This article is an open access article distributed under the terms and conditions of the Creative Commons Attribution (CC BY) license (https:// creativecommons.org/licenses/by/ $4.0 /)$.

\begin{abstract}
The main drawback of the Cascaded-H Bridge converter based on three-phase/singlephase current-source inverters is the large DC inductors needed to limit the variation of the DC current caused by the single-phase inverter oscillating power. If the oscillating power is somehow compensated, then the DC inductor can be designed just as a function of the semiconductors' switching frequency, reducing its value. This work explores the use of three-phase/single-phase cells magnetically coupled through their DC links to compensate for the oscillating power among them and, therefore, reduce the DC inductor value. At the same time, front ends controlled by a non-linear control strategy equalize the DC currents among coupled cells to avoid saturating the magnetic core. The effectiveness of the proposal is demonstrated using mathematical analysis and corroborated by computational simulation for a $110 \mathrm{kVA}$ load per phase and experimental tests in a 2 kVA laboratory prototype. The outcomes show that for the tested cases, coupling the DC links by a 1:1 ratio transformer allows reducing the DC inductor value below $20 \%$ of the original DC inductor required. The above leads to reducing by $50 \%$ the amount of magnetic energy required in the DC link compared to the original topology without oscillating power compensation, keeping the quality of the cell input currents and the load voltage.
\end{abstract}

Keywords: cascaded H-Bridge; current-source inverter; non-linear control; oscillating power compensation

\section{Introduction}

The Cascaded H-bridge (CHB) topology is a multilevel voltage-source-based configuration that uses several single-phase and series-connected inverters to reach a higher voltage level than the output level of each cell [1-3]. The main advantages of CHB are (i) modular construction of the power topology using cells, which reduces costs and makes replacement and reparation easier [4], and (ii) the low distortion of the output voltage [5,6]. $\mathrm{CHB}$ is a popular topology for medium voltage ac drives [7,8]. It is also typically used for active power filter applications as in the STATCOM $[9,10]$ and non-renewable energy integration to the electrical grid [11-13].

A Current-Source Inverter (CSI)-based CHB has been documented in recent years. The topology, also named CHB-CSI $[14,15]$, uses $n_{C}$ single-phase CSI in a cascaded array per phase, allowing the use of devices with a standard voltage rating to feed a load with high voltage. Each cell has an output capacitor that enables both the compensation of voltage harmonics and the achievement of a higher load voltage than each cell's output voltage, containing less distortion than each output alone. Thus, CHB-CSI could be used for the 
same applications of classic CHB topology, as an AC drive [16] and active power filters, among others, achieving advantages of the current-source topology such as low distortion at the input currents and outputs voltages, and inherent short circuit protection due to the use of a large inductor in the DC link [17]. As a result of the single-phase inverters, the main drawback of $\mathrm{CHB}$ topologies is the oscillating power drained by each inverter from its DC link, which leads to an unwanted oscillation in the DC variable [18-21]. This unwanted oscillation can be reduced by increasing the DC accumulator value, but in the CHB-CSI case and because the DC accumulator is an inductor, it also increases the losses, size, and weight of the cell $[22,23]$.

This work studies a CHB-CSI converter that uses magnetic couplings among the DC links to compensate the oscillating power among them and, therefore, decrease the DC inductor value required in each cell. Due to the use of an additional magnetic device in the DC link, the reduction is explored using the area product of the DC inductors and the coupling transformers, which allow defining the volume, weight, and footprint of each magnetic device, and comparing them with the area product, volume, weight, and footprint of the DC inductor required for the original CHB-CSI topology presented in [16]. This document is arranged as follows: first, the CHB-CSI topology is studied in Section 2, using the state model. The effect of the oscillating power drained by the single-phase inverter into the DC current is also analyzed, including the effect of the DC current oscillation on the DC inductor design. The effectiveness of magnetic coupling among CSI cells at compensating for the oscillating power is analyzed in Section 3, demonstrating the power compensation that occurs when three cells connected to different phases of the load are magnetically coupled by their DC links through a 1:1 ratio transformer. Section 4 defines a control strategy to equalize the DC current levels among magnetically coupled cells in order to avoid the transformer cores saturation and control the load voltage as well as the displacement power factor of the whole topology. Section 5 presents the design of the magnetic devices in the DC link, including (i) the DC inductor for the original case (i.e., CSI cells without oscillating power compensation strategy) and (ii) the DC inductor and the transformer for the proposal (i.e., CSI cells with an oscillating power compensation strategy). In addition, design considerations for the magnetic coupling transformers are reviewed. The area product is used to evaluate the DC inductor value reduction, including a reduction of its volume, weight, and footprint. Section 6 presents a case study based on computational simulation, where the reduction of the DC inductor is studied and compared to the original topology considering several cells per phase. In addition, the static and dynamic performances of the CHB-CSI are simulated to corroborate the accurate operation of the proposal, the oscillating power compensation, and the quality of its output voltage. Section 7 presents experimental results for a $2 \mathrm{kVA}$ laboratory prototype to demonstrate the proposal's implementation feasibility. Section 8 presents a brief comparison of the proposed topology with the original CHB-CSI topology, and Section 9 presents the conclusions.

The main contribution of this work is to demonstrate that it is feasible to reduce the value of the DC inductors in a CHB-CSI topology using magnetic couplings among cells and an appropriate control scheme to equalize the DC currents among the coupled cells. Based on the area product, it can be concluded that the amount of magnetic energy required for the proposal is less than that required for the original CHB-CSI configuration. The sum of the volume and weights of the DC magnetic devices (i.e., DC inductor and 1:1 ratio transformer) for the proposed case is also less than the volume and weight of the DC inductor value required in the original topology.

\section{CHB-CSI and the Oscillating Power Issues}

\subsection{CHB-CSI Converter}

In a CHB topology based on current-source inverters, $3 n_{C}$ cells are connected in series to increase the load voltage level $v_{L}$, as shown in Figure 1a [16]. Hence, the load voltage 
of the phase $j$ is the summation of the voltage in the $n_{C}$ single-phase inverters and their capacitive filters connected to the phase,

$$
v_{L}^{j}=\sum_{i=1}^{n_{C}} v_{o i}^{j}
$$

where $i$ is for the $i$-th cell that feeds the phase $j$ of the load, and $v_{o i}^{j}$ is the voltage of the cell across the output capacitor $C_{o}$ (see Figure $1 b$ ). Each inverter and its capacitor work as a controlled voltage source, and the dynamic of this voltage is defined by

$$
\frac{d}{d t} v_{o i}^{j}=\frac{1}{C_{o}}\left(i_{L}^{j}+s_{i i}^{j} i_{d c i}^{j}\right),
$$

where $i_{L}^{j}$ is the load current in the phase $j, s_{i i}^{\prime j}$ is the inverter switching function, and $i_{d c i}^{j}$ is the DC current of the $i$-th cell. Each inverter is fed by an isolated DC link and implemented using a DC inductor $L_{d c}$ and a three-phase current-source rectifier. The DC link can be modeled by:

$$
\left[\mathbf{s}_{\mathbf{r i}}^{a b c}\right]^{\mathrm{T}} \mathbf{v}_{\mathbf{c} i}^{a b c}=L_{d c} \frac{d}{d t} i_{d c i}^{j}+s_{i i}^{j} v_{o i}^{j}
$$

where $\mathbf{s}_{\mathbf{r} i}^{a b c, j}$ is the rectifier switching function vector and $\mathbf{v}_{\mathbf{c} i}^{a b c, j}$ is the voltage of the $L C$ filter at the $\mathrm{AC}$ side of the rectifier, which is connected to the $\mathrm{AC}$ mains by a transformer with $3 n_{C}$ three-phase secondary windings to step down the voltage level at the input of the power cells and to isolate the cells among them. Thus, the input of the cell can be modeled as

$$
\begin{gathered}
\mathbf{v}_{\mathbf{s} i}^{a b c, j}=L_{c} \frac{d}{d t} \mathbf{i}_{\mathbf{c} i}^{a b c, j}+\mathbf{v}_{\mathbf{c} i}^{a b c, j}, \\
\mathbf{i}_{\mathbf{c} i}^{a b c, j}=C_{\mathbf{c}} \frac{d}{d t} \mathbf{v}_{\mathbf{c} i}^{a b c, j}+\mathbf{s}_{\mathbf{r} i}^{a b c, j} i_{d c i}^{j},
\end{gathered}
$$

where $\mathbf{v}_{s i}^{a b c, j}$ is the supply voltage of the cell, $\mathbf{i}_{\mathbf{c} i}^{a b c, j}$ is the input current of the cell. Defining the average value of the switching functions $\mathbf{s}_{\mathbf{r} i}^{a b c, j}$ and $s_{i i}^{\prime j}$ as a function of the modulation indexes $\mathbf{m}_{\mathbf{r} i}^{a b c, j}$ and $m_{i i}^{\prime j}$, then

$$
\begin{gathered}
\mathbf{s}_{\mathbf{r i}}^{a b c, j} \approx G_{r i}^{j} \mathbf{m}_{\mathbf{r i}}^{a b c, j}, \\
s_{i i}^{j} \approx m_{i i}^{j}=G_{i i}^{j} M_{i i}^{j} \sin \left(\omega_{i} t+\alpha_{j}\right),
\end{gathered}
$$

where $G_{r i}^{j}$ and $G_{i i}^{j}$ are the fundamental component gain of the modulation technique for the rectifier and the inverter respectively, $f_{i}$ is the inverter frequency and defines $\omega_{i}=2 \pi f_{i}$, and $\alpha_{j}$ is the inverter phase-lag.

\subsection{Oscillating Power Issues}

Focusing the analysis on a single cell and omitting $i$ and $j$ for simplicity, the power $p_{o}$ drained from the DC link by the single-phase inverter (see Figure 1c) is given by the summation of a continuous power component $\overline{p_{o}}$ and an oscillating power component $\widetilde{p_{0}}$; thus,

$$
p_{o}=\overline{p_{o}}+\widetilde{p_{o}}=\underbrace{\frac{Z_{m}\left(\omega_{i}\right) I_{d c}{ }^{2} M_{i}{ }^{2}}{2}}_{S_{o}}\left(\cos \left(\phi_{m}\right)-\cos \left(2 \omega_{i} t+2 \alpha_{j}+\phi_{m}\right)\right),
$$

where $Z_{m}\left(\omega_{i}\right)$ is the equivalent parallel impedance of the load and the capacitive filter, and $\phi_{m}$ is the angle of $Z_{m}\left(\omega_{i}\right)$. The continuous power component $\overline{p_{o}}$ is provided by the rectifier stage, whereas the oscillating component $\widetilde{p_{0}}$ is typically provided by the dc inductor and the 
rectifier. The oscillating power causes an oscillation in the dc current with a $2 f_{i}$ frequency (see Figure 1d) that can be calculated from

$$
\frac{L_{d c}\left[i_{d c}\left(t_{2}\right)^{2}-i_{d c}\left(t_{1}\right)^{2}\right]}{2\left(t_{2}-t_{1}\right)}=p_{o}\left(t_{2}\right)-p_{o}\left(t_{1}\right) .
$$

Using (9) and considering Figure $1 \mathrm{~d}$, let us assume that $i_{d c}\left(t_{1}\right)=I_{d c}$ and $i_{d c}\left(t_{2}\right)=I_{d c} k_{d c}$, where $k_{d c}$ is the DC current variation, per unit, between $t_{1}$ and $t_{2}$. Then, if $k_{d c}=1$, there is no DC current variation between $t_{1}$ and $t_{2}$, while if $k_{d c} \neq 1$, there is a DC current variation between $t_{1}$ and $t_{2}$. For an inverter frequency $\omega_{i}$, the peak value of $k_{d c}$ is given by

$$
k_{d c}=\sqrt{1+\frac{\pi}{8 \omega_{i}} \frac{Z_{m}\left(\omega_{i}\right) M_{i}^{2}}{L_{d c}}}
$$

where $k_{d c}$ approaches 1 by increasing $L_{d c}$ for any $\omega_{i} \neq 0$. A 2 nd harmonic in the DC current has the following effects on the input and the output of the cell:

- At the load, the 2nd harmonic in the dc current generates a 3rd harmonic in the inverter output current, which can be amplified by the LC equivalent circuit of the output capacitor and the electrical machine inductance.

- At the input, the rectifier injects two current components around $f_{s} \pm 2 f_{i}$. These components can be compensated among cells in the input transformer but can also lead to resonance issues in the LC input filter. Additionally, these unwanted components increase the losses of the LC filter and the transformer secondary winding.

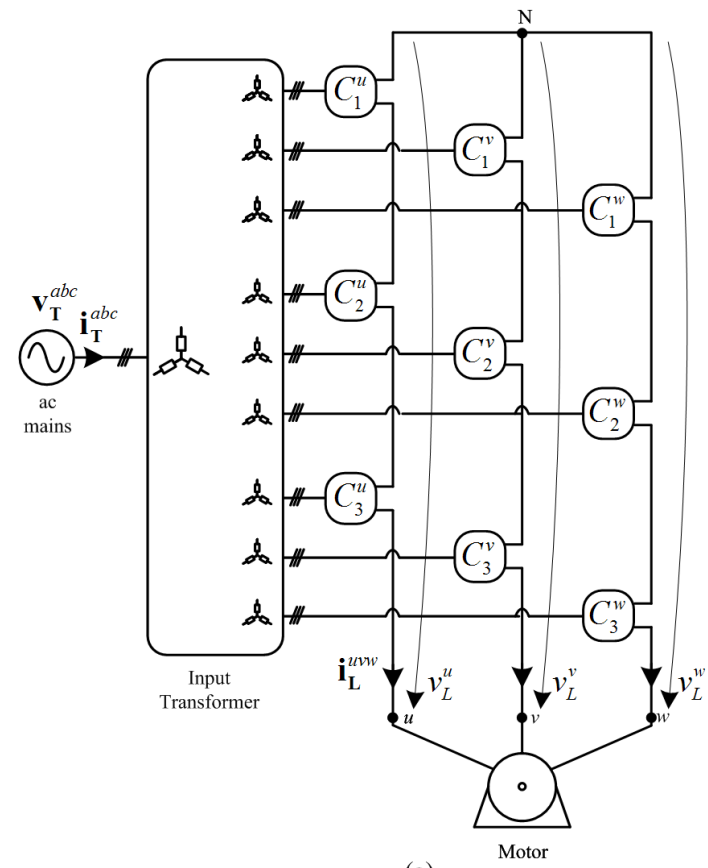

(a)

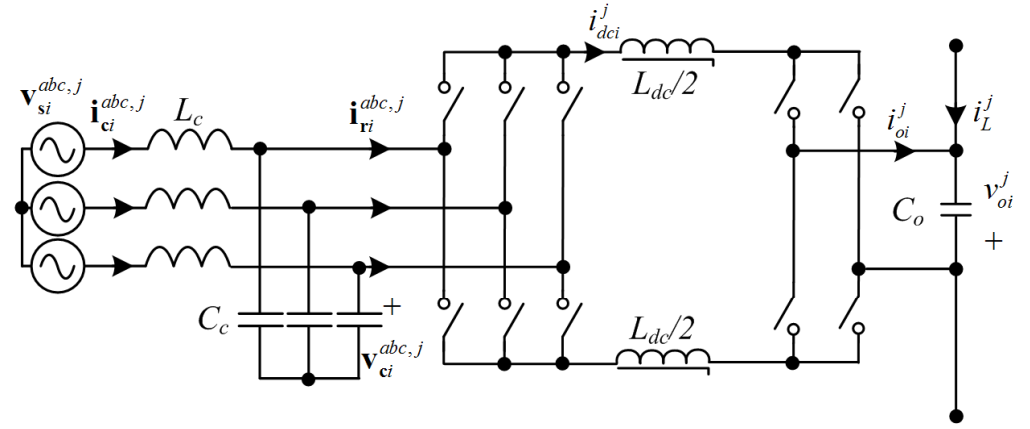

(b)

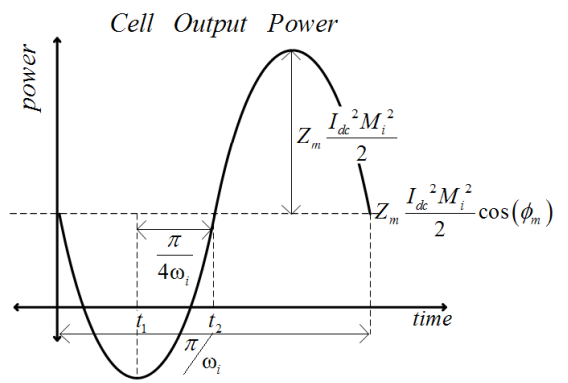

(c)

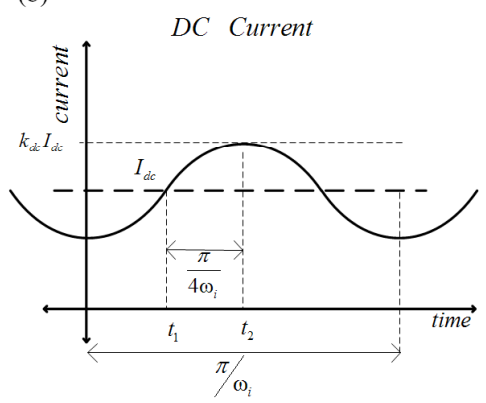

(d)

Figure 1. Cascaded H-bridge topology based on current-source inverters: (a) CHB-CSI, three cells per phase $\left(n_{C}=3\right)$; (b) three-phase/single-phase current-source cell; (c) oscillating power drained by the inverter from the DC link; (d) DC current variation because of the oscillating power [16].

\section{CHB-CSI with Magnetic Coupling among DC Links in CSI Cells}

The proposed topology is shown in Figure 2, where the original cells presented in Figure $1 \mathrm{~b}$ are changed by three cells magnetically coupled by three transformers with a 1:1 ratio among their DC links. This connection allows compensating the magnetic field by 
zero-frequency of the DC currents between the coupled cells by the transformer. Suppose the three cells feed different phases of a three-phase load (i.e., the inverter voltages are $120^{\circ}$ phase-shifted). In that case, they can compensate for the even harmonics among them with a negative or positive sequence through the magnetic coupling. On the other hand, zerosequence harmonics (6th and its multiples) must be mitigated by the DC inductor [24-26]. The above-mentioned can be demonstrated using the mathematical model presented in (1) to (5) and considering the fundamental components of the switching function as they were presented in (6) and (7). Thus, and omitting $i$ for simplicity, the DC voltage of an inverter feeding the phase $j$ (Figure 2) is given by

$$
v_{i}^{j}=m_{i}^{j} v_{o}^{j}=\frac{M_{i}^{j} V_{o}^{o}}{2}\left[\cos \left(\phi_{m}\right)-\cos \left(2 \omega_{i} t+2 \alpha_{j}+\phi_{m}\right)\right],
$$

where $v_{o}^{j}$ is the fundamental amplitude of the cell output voltage. Conversely, if the magnetizing inductance and resistance are high enough, both can be neglected. Therefore, the harmonic voltages at the primary and secondary of each magnetic coupling are equal. If the magnetic couplings between the DC links have identical parameters, then

$$
L_{u w}=L_{v u}=L_{w v}=L
$$

where $L_{w u}, L_{u v}$, and $L_{v w}$ are the mutual inductances between cells. It is known that the mutual inductance for magnetic coupling between two identical windings is

$$
M=k \sqrt{L^{2}},
$$

where if the coupling factor $k=1, L$ is equal to $M$ for each device $(M=L)$. Hence, the coupling voltages shown in Figure 2 can be written as

$$
\left[\begin{array}{c}
v_{M}^{u v} \\
v_{M}^{v w} \\
v_{M}^{w u}
\end{array}\right]=-\left[\begin{array}{c}
v_{M}^{v u} \\
v_{M}^{w v} \\
v_{M}^{u w}
\end{array}\right]=M\left[\begin{array}{ccc}
1 & -1 & 0 \\
0 & 1 & -1 \\
-1 & 0 & 1
\end{array}\right]\left[\begin{array}{l}
\frac{d}{d t} i_{d c}^{u} \\
\frac{d}{d t} i_{d c}^{v} \\
\frac{d}{d t} i_{d c}^{w}
\end{array}\right] .
$$

From (14) and using the Kirchhoff Voltage Law for each DC link, it is possible to write

$$
\begin{aligned}
& v_{r}^{u}=v_{z}^{u}-v_{M}^{w u}+v_{i}^{u}+v_{M}^{u v}, \\
& v_{r}^{v}=v_{z}^{v}-v_{M}^{u v}+v_{i}^{v}+v_{M}^{v w}, \\
& v_{r}^{w}=v_{z}^{w}-v_{M}^{v w}+v_{i}^{w}+v_{M}^{w u},
\end{aligned}
$$

where $v_{z}^{j}$ is the voltage in the impedance $Z_{j}$, which includes the DC inductor components (inductance $L_{d c}$ and resistance $R_{d c}$ ) and the transformer's leakage impedance. If the DC link impedances are identical, then

$$
v_{z}=v_{z}^{u}=v_{z}^{v}=v_{z}^{w}
$$

From the previous equations, it is possible to determine that the $v_{z}$ in each coupled cell satisfies

$$
v_{z}=\frac{1}{3}\left[\left(v_{r}^{v}+v_{r}^{v}+v_{r}^{w}\right)-\left(v_{i}^{u}+v_{i}^{v}+v_{i}^{w}\right)\right] .
$$

Now, using (11) and assuming-just for simplicity- $\phi_{m}=0$, each coupled cell inverter voltage can be written as

$$
\begin{gathered}
v_{i}^{u}=\frac{M_{i}^{u} V_{o}^{u}}{2}\left(1-\cos \left(2 \omega_{i} t\right)\right) \\
v_{i}^{v}=\frac{M_{i}^{v} V_{o}^{v}}{2}\left(1-\cos \left(2 \omega_{i} t-\frac{2}{3} \pi\right)\right),
\end{gathered}
$$




$$
v_{i}^{w}=\frac{M_{i}^{w} V_{o}^{w}}{2}\left(1-\cos \left(2 \omega_{i} t+\frac{2}{3} \pi\right)\right) .
$$

Then, replacing (20), (21), and (22) in (19), it follows that

$$
v_{z}=\frac{1}{3}\left[\left(v_{r}^{u}+v_{r}^{v}+v_{r}^{w}\right)-\frac{1}{2}\left(M_{u} V_{o}^{u}+M_{v} V_{o}^{v}+M_{w} V_{o}^{w}\right)\right],
$$

where the oscillating terms in the inverter voltages are compensated because they are $120^{\circ}$ out of phase. The above is valid only if (i) the DC current levels in each cell are equal, (ii) the cells' parameters are equal, and (iii) the fundamental voltages and currents in the load side of each cell are equal. Therefore, it is necessary to design the DC cells' parameters and a suitable control strategy to ensure equal DC currents and the cell output voltages.

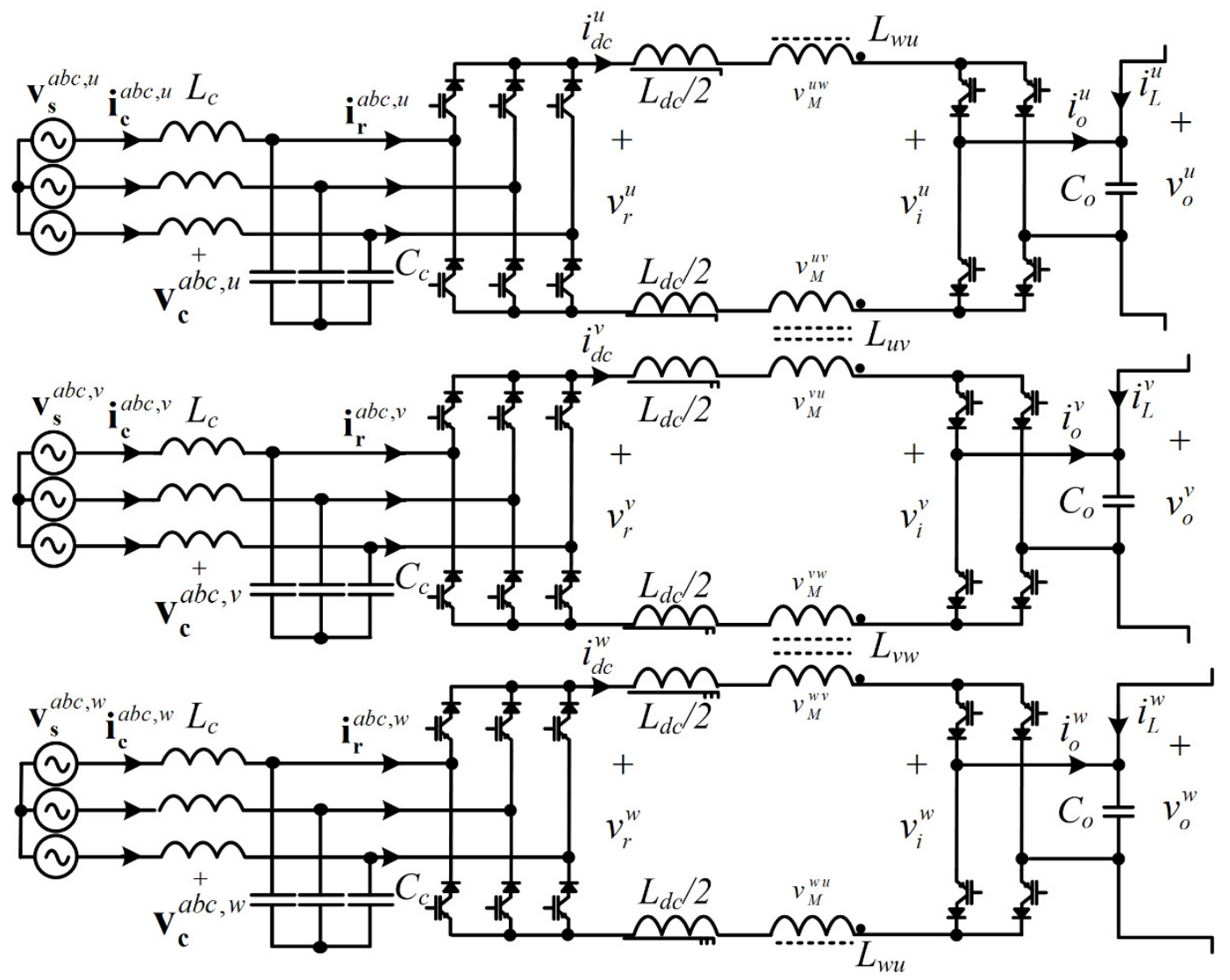

Figure 2. Three cells magnetically coupled by their DC links.

\section{Control Scheme}

\subsection{About the Control Strategy}

For the magnetically coupled cells, it is necessary to ensure that the transformer cores do not operate near to saturation levels. Overall, the control objectives of the whole topology are (i) the load voltage level and (ii) to keep the reactive power at the input of the converter within the desired range or even get a displacement power factor near or equal to unitary. To avoid saturation of the magnetic coupling and control the load voltage by the DC currents, it is necessary to equalize the DC currents among the coupled cells. From the control point of view, this implies that the DC current must be controlled evenly in all the coupled cells and ensure that the instantaneous current values are equal during transient conditions. This strategy allows using a fixed modulation in the inverter, setting the load frequency and phase lag by this modulation. At the same time, the rectifier controls the DC current and the cell reactive power. 
Non-linear control strategies such as input/output linearization [27] allow controlling the current-source rectifier without considering a fixed operating point, which strongly depends on the DC current level. This strategy focuses on controlling the rectifier input currents, and, based on these currents, the control of the active and reactive power is achieved. The control of the output voltage $v_{0}$ manages the inverter states and determines the DC current references for every cell. In this case, the reactive power at the rectifier can be set to the desired value (zero, to achieve a unitary power factor in this work).

The control scheme for each cell is shown in Figure 3. To define the non-linear control laws, a $d q$ frame state-space model is required. Using the Park transform for (2)-(5), and omitting $i$ and $j$, each cell can be mathematically modeled by

$$
\begin{gathered}
\mathbf{v}_{\mathbf{s}}^{d q}=L_{c} \frac{d}{d t} \mathbf{i}_{\mathbf{c}}^{d q}+L_{c} \mathbf{W i}_{\mathbf{c}}^{d q}+\mathbf{v}_{\mathbf{c}}^{d q}, \\
\mathbf{i}_{\mathbf{c}}^{d q}=C_{c} \frac{d}{d t} \mathbf{v}_{\mathbf{c}}^{d q}+C_{c} \mathbf{W} \mathbf{v}_{\mathbf{c}}^{d q}-G_{r} \mathbf{m}_{\mathbf{r}}^{d q} i_{d c}, \\
G_{r}\left[\mathbf{m}_{\mathbf{r}}^{d q}\right]^{T} \mathbf{v}_{\mathbf{c}}^{d q}=L_{d c} \frac{d}{d t} i_{d c}+i_{d c} M_{i} \sin \left(\omega_{i} t+\alpha_{j}\right),
\end{gathered}
$$

where

$$
\mathbf{W}=\left[\begin{array}{cc}
0 & -\omega_{s} \\
\omega_{s} & 0
\end{array}\right]=\left[\begin{array}{cc}
0 & -2 \pi f_{s} \\
2 \pi f_{s} & 0
\end{array}\right]
$$

\subsection{Cell Input Currents Controller}

Cell input currents are controlled using the rectifier. To get a decoupled control, rectifier modulators $\mathbf{m}_{\mathbf{r}}^{d q}$ are defined by

$$
\mathbf{m}_{\mathbf{r}}^{d q}=\frac{1}{A_{c}}\left[D_{c} \mathbf{u}_{\mathbf{c}}^{d q}+\mathbf{F}_{\mathbf{c}}\left[\begin{array}{c}
\mathbf{i}_{\mathbf{c}}^{d q} \\
\frac{d}{d t} \mathbf{i}_{\mathbf{c}}^{d q}
\end{array}\right]-\mathbf{B}_{\mathbf{c}}\left[\begin{array}{c}
\mathbf{x}_{\mathbf{c}} \\
\mathbf{p}_{\mathbf{s}} \\
\frac{d}{d t} \mathbf{p}_{\mathbf{s}}
\end{array}\right]\right]
$$

where

$$
\begin{aligned}
& \mathbf{x}_{\mathbf{c}}=\left[\begin{array}{lllll}
i_{c}^{d} & i_{c}^{q} & v_{c}^{d} & v_{c}^{q} & i_{d c}
\end{array}\right]^{T}, \\
& \mathbf{p}_{\mathbf{s}}=\left[\begin{array}{ll}
v_{S}^{d} & v_{s} q
\end{array}\right]^{T} \text {, } \\
& A_{c}=G_{r} i_{d c} /\left(C_{c} L_{c}\right) \text {, } \\
& \mathbf{B}_{\mathbf{c}}=\left[\begin{array}{cc}
-\omega_{s}^{2}-\omega_{L C}{ }^{2} & 0 \\
0 & -\omega_{s}^{2}-\omega_{L C}{ }^{2} \\
0 & 2 \omega_{s} / L_{c} \\
-2 \omega_{s} / L_{c} & 0 \\
0 & 0 \\
0 & -2 \omega_{s} / L_{c} \\
2 \omega_{s} / L_{c} & 0 \\
1 / L_{c} & 0 \\
0 & 1 / L_{c}
\end{array}\right]^{T} \\
& D_{c}=k_{2} \text {, } \\
& \mathbf{F}_{\mathbf{c}}=\left[\begin{array}{cccc}
-k_{2} & 0 & -k_{1} & 0 \\
0 & -k_{2} & 0 & -k_{1}
\end{array}\right] \text {, }
\end{aligned}
$$

and $\mathbf{u}_{\mathbf{c}}^{d q}$ is an auxiliary variable that allows relating the dynamic of the cell input currents with the modulators. This strategy, combined with a proportional controller, can be used to define the input current dynamic, but this is only possible if the parameters in (31) and (32) are exactly the same as the actual parameters. To compensate for the small parameters' 
deviations, an integrator is included to relate the current references $\mathbf{i}_{\mathbf{c}, \text { ref }}^{d q}$ and the auxiliary variable $\mathbf{u}_{\mathbf{c}}^{d q}$ in such a manner that

$$
\frac{u_{c}^{d}}{i_{c . r e f}^{d}}=\frac{u_{c}^{q}}{i_{c . r e f}^{q}}=\frac{1}{T_{i . i_{c}} s} .
$$

Then, a third-order transfer function between $\mathbf{i}_{\mathbf{c}, \text { ref }}^{d q}$ and $\mathbf{i}_{\mathbf{c}}^{d q}$ is obtained, which includes the second-order passive LC filter and the integrative control dynamic. The overall current control dynamic is defined by $k_{1}, k_{2}$, and $T_{i . i c}$ as follows:

$$
\frac{i_{c}^{d}}{i_{c . r e f}^{d}}=\frac{i_{c}^{q}}{i_{c . r e f}^{q}}=\frac{k_{2}}{T_{i . i_{c}}} \frac{1}{s^{3}+k_{1} s^{2}+k_{2} s+k_{2} / T_{i . i_{c}}}
$$

One option to set the dynamic of the third-order system is the Integral Time Absolute Error criterion [28] which defines $k_{1}, k_{2}$ and $T_{i . i_{c}}$ as a function of the desired settling time $t_{\text {s. } i_{c}}$. Thus,

$$
\begin{gathered}
k_{1}=13.195 / t_{s . i_{c^{\prime}}}, \\
k_{2}=122.231 / t_{s . i_{c}}{ }^{2}, \\
T_{i . i_{c}}=0.285 t_{\text {s. } i_{c}} .
\end{gathered}
$$

\subsection{Current Controller}

If the Park transform is synchronized with the cell input voltage, which means $v_{s}{ }^{q}=0$, then the cell input active power can be defined as

$$
p_{c e l l}=v_{s}^{d} i_{c}^{d}
$$

and therefore, the DC current can be controlled using $i_{\mathrm{c}}^{d}$. To define a non-linear control law, a power balance between the input of the cell and the DC link power can be written as

$$
p_{c e l l}=-L_{d c} i_{d c} \frac{d}{d t} i_{d c}-i_{d c}^{2} R_{d c}-\overline{p_{0}},
$$

where $\overline{p_{0}}$ is defined in (8). In a similar way to the cell input current controller, an auxiliary variable, $u_{i_{d c}}$ defined by

$$
u_{i d c}=L_{d c} \frac{d}{d t} i_{d c},
$$

Is used to relate the $i_{d c}$ dynamic with a controller. From (40) and (41), it can be related $u_{i_{d c}}$ to the reference of $i_{c}^{d}$, leading to

$$
i_{c . r e f}^{d}=\frac{1}{v_{s}^{d}}\left[u_{i_{d c}} i_{d c}-i_{d c}^{2} R_{d c}-\overline{p_{o}}\right],
$$

and relating the difference between an auxiliary reference for the dc current $i_{d c . r e f}^{*}$, the dc current $i_{d c^{\prime}}$ and $u_{i_{d c}}$ using a PI regulator,

$$
\frac{u_{i_{d c}}}{i_{d c . r e f}^{*}-i_{d c}}=k_{p \cdot i_{d c}}+\frac{k_{i . i_{d c}}}{s} .
$$

The auxiliary reference, $i_{d c . r e f}^{*}$, is required because by the use of a PI regulator, a second-order transfer function given by

$$
\frac{i_{d c}}{i_{d c . r e f}^{*}}=\frac{k_{i . i_{d c}}+k_{p \cdot i_{d c}} s}{L_{d c} s^{2}+k_{p . i_{d c}} s+k_{i . i_{d c}}}
$$


is obtained. To compensate the zero in (45), a first-order filter defined by

$$
\frac{i_{d c . r e f}^{*}}{i_{d c . r e f}}=k_{i . i_{d c}} \frac{1}{k_{i . i_{d c}}+k_{p . i_{d c} s} s},
$$

can be used, transforming (45) into a standard second-order function and allowing designing the PI parameters as a function of a damping ratio $\zeta_{d c}$ and a desired natural frequency $\omega_{o . i_{d c}}$. Thus,

$$
\begin{gathered}
k_{i . i_{d c}}=\omega_{o . i_{d c}}{ }^{2} L_{d c}, \\
k_{p . i_{d c}}=2 \zeta_{i_{d c}} \sqrt{L_{d c} k_{i . i_{d c}}} .
\end{gathered}
$$

Equation (43) sets the reference for the cell input controller, so a settling time of 5 times $t_{\text {s.ip }}$ or higher is recommended.

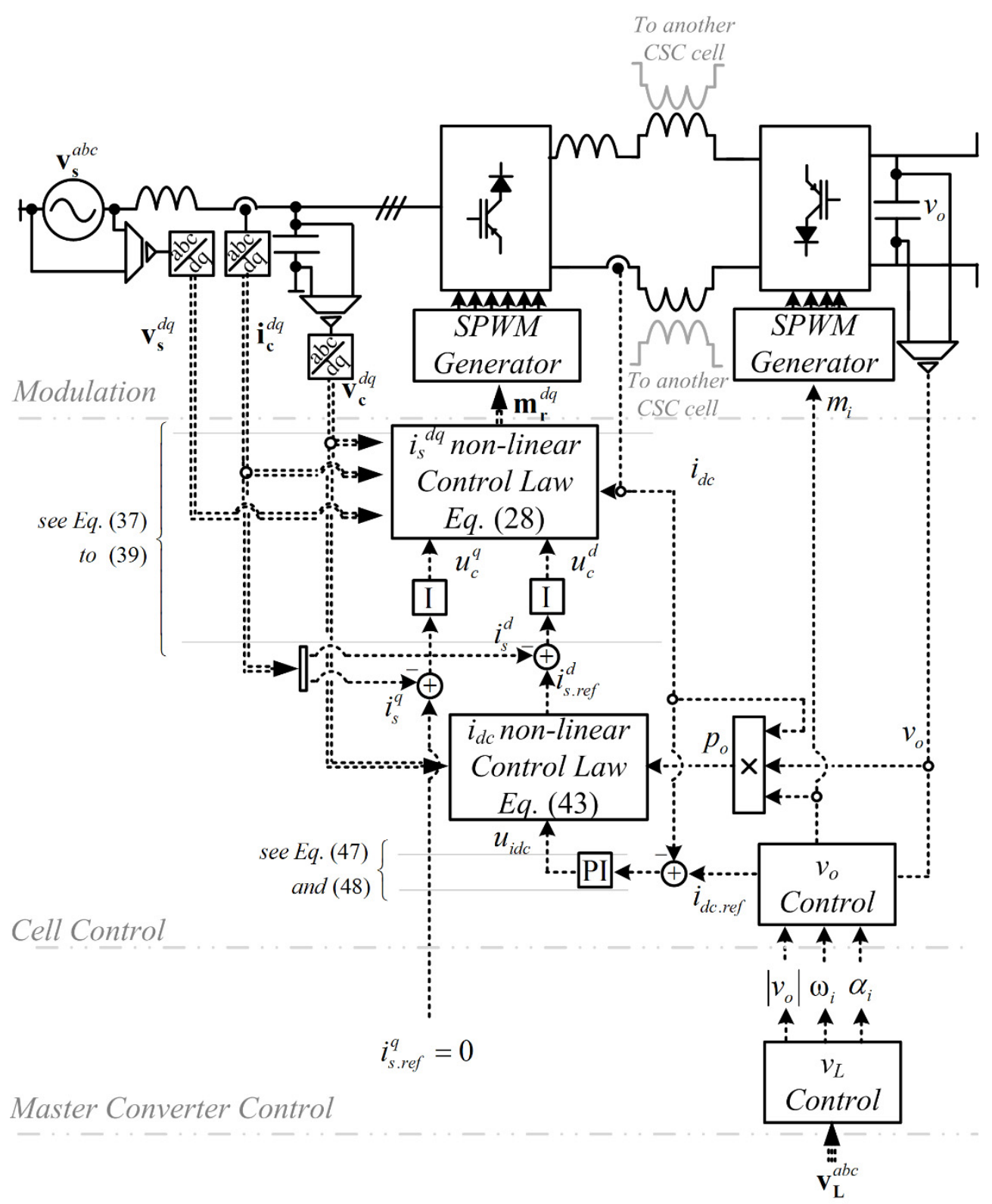

Figure 3. Control scheme for each cell. 


\subsection{Cell Reactive Power Controller}

At the input of each cell, the reactive power can be defined in terms of the $d q$ axis as

$$
q_{c e l l}=-v_{s}^{d} i_{c}^{q}
$$

As $i_{c}^{q}$ has been controlled by using (35) and $v_{s}^{d}$ is well known (because it is used in (28)), it is easy to define a reference to $i_{\mathrm{c}}^{q}$ from (49). Likewise, a displacement power factor for the whole converter can be set. In this work and just for simplicity, $i_{c . r e f}^{q}=0$ is set for the unitary displacement power factor at the input of each cell.

\subsection{Load Voltage Controller}

When DC currents are controlled and equalized by the controllers of the rectifiers, the load voltage can be controlled through the DC current in each cell. Thus, the reference of the load voltage per phase is divided by the number of cells and used as a reference for the output voltage controller of each cell. The phase and frequency are imposed by each inverter's modulation.

\section{DC Inductor and Magnetic Coupling Design}

\subsection{Inductor Design}

For a CHB-CSI topology, there are two possible scenarios for the DC inductor design. In both cases, the DC current ripple must be limited. In the first scenario, the DC inductor must be designed to compensate for the oscillating power, with the DC current ripple mainly a function of this power component, as presented in Section II.B. From (10), the ripple by the inverter 2 nd harmonic can be limited through the DC inductor sizing. Then, for a $1-k_{d c}$ variation (Figure $1 c$ ), $L_{d c}$ can be computed as

$$
L_{d c}=\frac{1}{n_{C}} \frac{\pi}{8 \omega_{i}} \frac{Z_{m} M_{i}^{2}}{\left(k_{d c}^{2}-1\right)} .
$$

The second scenario involves the oscillating power compensation without using a DC inductor, with the ripple mainly a function of the power converter commutation frequency, $f_{C}$ [29]. This is the case for the magnetically coupled cells, for which the DC current ripple can be defined, per unit, as $\delta$. Then,

$$
L_{d c_{-} \text {Reduced }} \approx \frac{\sqrt{6} v_{s, r m s}-\frac{V_{0}}{2}}{4 \delta I_{d c} f_{C}}=\frac{\sqrt{6} v_{s, r m s}-\frac{S_{0} \cos \left(\phi_{m}\right)}{2 I_{d c}}}{4 \delta I_{d c} f_{C}} .
$$

\subsection{Coupling Transformer Design}

From Section 3, a coupling transformer with a 1:1 ratio is required to compensate for the oscillating power among the cells. In addition, it is possible to define the apparent power, $S_{t}$, and voltage, $V_{t}$, of the transformer as a function of the inverter power $S_{o}$ and the DC current; thus,

$$
\begin{aligned}
& S_{t}=S_{o} / \sqrt{3}, \\
& V_{t}=S_{t} / I_{d c} .
\end{aligned}
$$

\subsection{Area Product Relation between Magnetic Devices}

For a magnetic core, the area product $-A_{p}$-is defined as the product of the core windows area and a core cross-section area. Since the area product is well documented by core manufacturers, the relation of this term between two magnetic devices can help to compare magnetic devices in terms of size, weight, and cost. For the DC inductor, the original DC inductor required is mainly a function of the oscillating power, while the second is a function of the converters' switching frequency. To compare the two DC inductor values, 
the amount of magnetic energy required by each magnetic device is computed. This energy can be written in terms of the area product, $A_{p}$, which is defined for a DC inductor by [30] as

$$
A_{p, L_{d c}}=\frac{I_{d c}^{2} L_{d c}}{k_{w} B J} 10^{4}\left(\mathrm{~cm}^{4}\right),
$$

where $k_{w}$ is the utilization factor, $B$ is the magnetic induction, and $J$ is the current density. If the inductors are built using the same magnetic material and electric conductors, the relation $R_{L_{d c}}$ can be reduced to

$$
R_{L_{d c}}=\frac{A_{p, L_{d c \_ \text {Reduced }}}}{A_{p, L_{d c \_ \text {Original }}}}=\frac{L_{d c_{\_} \text {Reduced }}}{L_{d c_{-} \text {Original }}}(\text { p.u. }) .
$$

On the other hand, the area product can also be used in order to compare the amount of magnetic energy required by the coupling transformers to the original DC inductor. In this case, the coupling transformer area product is defined by [30] as

$$
A_{p, M a g C o u}=\frac{S_{o}}{2 \sqrt{6} k_{w} J f_{i} B} 10^{4}\left(\mathrm{~cm}^{4}\right) .
$$

Thus, the relation $R_{M a g C o u}$ between the area product of the original DC inductor and the coupling transformer, considering that both devices use the same type of electrical conductor and magnetic material, is given by

$$
R_{\text {MagCou }}=\frac{A_{p, \text { MagCou }}}{A_{p, L_{d L_{\_} \text {original }}}}=\frac{S_{o}}{\sqrt{6} f_{i} I_{d c}^{2} L_{d c}} \text { (p.u.). }
$$

\begin{tabular}{|c|c|c|c|c|}
\hline Magnetic Devices & Area Product Relation & Volume Relation & Weight Relation & Footprint Relation \\
\hline$L_{d c}$ Original & $\frac{L_{d c_{-} \text {Original }}}{L_{d c_{-} \text {Original }}}=1$ p.u. & $\left(\frac{L_{d c_{-} \text {Original }}}{L_{d c_{-} \text {Original }}}\right)^{3 / 4}=1$ p.u. & $\left(\frac{L_{d c_{-} \text {Original }}}{L_{d c_{\text {_OAriginal }}}}\right)^{3 / 4}=1$ p.u. & $\left(\frac{L_{d c_{-} \text {Original }}}{L_{d c_{-} \text {Original }}}\right)^{1 / 2}=1$ p.u. \\
\hline$L_{d c}$ Reduced & $\frac{L_{d c \_ \text {Reduced }}}{L_{d c_{-} \text {Original }}}$ & $\left(\frac{L_{d c \_ \text {Reduced }}}{L_{d c_{-} \text {Original }}}\right)^{3 / 4}$ & $\left(\frac{L_{d c \_ \text {Reduced }}}{L_{d c \_ \text {Original }}}\right)^{3 / 4}$ & $\left(\frac{L_{d c \_ \text {Reduced }}}{L_{d c \_ \text {original }}}\right)^{1 / 2}$ \\
\hline DC Link Coupling Transformer & $\frac{S_{o}}{\sqrt{6} f_{h} I_{d c}^{2} L_{d c_{-} \text {Original }}}$ & $\left(\frac{s_{o}}{\sqrt{6} f_{h} I_{d c}^{2} L_{d c_{-} \text {Original }}}\right)^{3}$ & $\left(\frac{S_{o}}{\sqrt{6} f_{h} I_{d c}^{2} L_{d c_{-} \text {Original }}}\right)^{3}$ & $\left(\frac{S_{o}}{\sqrt{6} f_{h} I_{d c^{2} L_{d c_{-} \text {Original }}}}\right)^{1}$ \\
\hline
\end{tabular}

The above relations are summarized in Table 1 .

Table 1. Relation of area product, volume, weight, and footprint between reduced DC inductor and magnetic coupling, and the original DC inductor.

5.4. Effect of the DC Inductor Reduction in the Weight, Volume, and Footprint Required in the DC Link

From [30], it is possible to estimate the volume $(\mathrm{Vol})$, weight $(W)$, and footprint $\left(A_{t}\right)$ of a magnetic device based on its area product $\left(A_{p}\right)$ using the following expressions

$$
\begin{gathered}
V o l=k_{\text {vol }} A_{p}^{3 / 4} \quad\left(\mathrm{~cm}^{3}\right), \\
W=k_{w} A_{p}^{3 / 4} \quad(\mathrm{gr}) \\
A_{t}=k_{s} A_{p}^{1 / 2} \quad\left(\mathrm{~cm}^{2}\right)
\end{gathered}
$$

where $k_{v o l}, k_{w}$, and $k_{s}$ are parameters defined by the core material of the magnetic device. Then, considering the use of the same material for all the magnetic devices and using (55) and (57), the relation for the volume, weight, and footprint between the DC inductor and magnetic coupling and the original DC inductor can be computed [31] (see Table 1). This expression allows referring the volume, weight, and footprint of the reduced DC inductor and the transformers to the volume, weight, and footprint of the original DC inductor. 


\section{Case of Study}

As a case of study, the reduction of the DC inductor and the performance of the power topology are tested for a $110 \mathrm{kVA}$ load per phase. Parameters are shown in Table 2.

Table 2. Simulation and experimental parameters.

\begin{tabular}{lcccc}
\hline \multicolumn{1}{c}{ Parameter } & \multicolumn{2}{c}{ Simulation Value } & \multicolumn{2}{c}{ Experimental Value } \\
\hline Load & $R_{l}$ & 40 & 11 & $\Omega$ \\
& $L_{l}$ & 80 & 24 & $\mathrm{mH}$ \\
Cell's Input Filter & $L_{s}$ & 12 & 12 & $\mathrm{mH}$ \\
& $C_{s}$ & 55 & 40 & $\mu \mathrm{F}$ \\
DC Inductor for $n_{C}=1$ without & $L_{d c}^{*}$ & 300 & - & $\mathrm{mH}$ \\
magnetic coupling & & & & \\
DC Inductor for $n_{C}=1$ with magnetic & $L_{d c}$ & 39 & 36 & $\mathrm{mH}$ \\
coupling & & & & \\
DC Inductor for $n_{C}=2$ with magnetic & $L_{d c}$ & 21 & - & $\mathrm{mH}$ \\
coupling & $C_{o}$ & 10 & 20 & $\mu \mathrm{F}$ \\
Output Capacitor & & 33 & 15 & $\mathrm{p.u}$. \\
Rectifier Modulating Frequency & & 12 & 10 & $\mathrm{p} \cdot \mathrm{u}$, \\
Inverter Modulating Frequency & & 7 & 7 & $\mathrm{~ms}$ \\
Settling Time Input Current Controller & $\omega_{o . i_{d c}}$ & 251,327 & 251,327 & $\mathrm{rad} / \mathrm{s}$ \\
DC Current Control & $\zeta_{i_{d c}}$ & 1 & 1 & \\
& & &
\end{tabular}

To analyze the reduction of the DC inductor, the design criteria presented in Section 5 is applied to both the original and the proposal topologies, computing the required DC inductors values for each case using one cell per load phase $\left(n_{C}=1\right)$ to five cells per load phase $\left(n_{C}=5\right)$. Then, the area products of the DC link magnetic devices related to the original DC inductors are computed in order to determine the reduction of volume, weight, and footprint achieved by the proposal.

To test the dynamic and steady-state performance, two cases were simulated in PSIM ${ }^{\circledR}$ 9.0, using one cell per load phase $\left(n_{C}=1\right)$ and two cells per load phase $\left(n_{C}=2\right)$, respectively, with the control scheme proposed in Section 4 . In order to show that the cell input voltage can be reduced, for $n_{C}=1$, each cell is fed with a $1480 \mathrm{~V}_{\text {rms }}$ line-to-line, while for $n_{C}=2$, the voltage supply is $740 \mathrm{~V}_{\text {rms }}$ line-to-line. Cells are magnetically coupled using an ideal transformer with a 1:1 ratio. For each case, the inductor was designed to obtain the same DC current ripple, while the parameters of the controllers are designed to achieve the same dynamic performance in each cell for both cases, $n_{C}=1$ and $n_{C}=2$. The simulated tests are focused on (i) demonstrating that the proposal is able to compensate the oscillating power by the magnetic coupling and equalize the dc currents among coupled cells, (ii) testing the performance of the oscillating power compensation under load frequency changes, and (iii) showing the power quality of the cell input currents and the load voltage.

\subsection{Analysis of the DC Inductor Reduction}

The DC inductors for the original topology and the proposed topology were computed for $n_{C}=1$ to $n_{C}=5$ in order to obtain a DC current ripple in the $10 \%$ band, using (50) for the original DC inductor $\left(L_{d c}\right.$ Original,$k_{d c}=1.1$, i.e., $10 \%$ of 2 nd harmonic DC current due to the oscillating power) and (51) for the DC inductor reduced case $\left(L_{d c}\right.$ Reduced,$\delta=0.1$, i.e., $10 \%$ of DC current variation due to the power converter commutations). The computed values are shown in Figure 4a. A reduction in both DC inductors' values is obtained when the number of cells increases but, for all the cases, $L_{d c}$ Original is higher than $L_{d c}$ Reduced. Specifically, for $n_{C}=1, L_{d c}$ Reduced is only $0.13(13 \%)$ of $L_{d c}$ Original .

The relation between the area product of these two inductors (see Table 1) can be observed in Figure $4 b$, where the reduction is always below 0.2 of $L_{d c}$ Original. Figure $4 \mathrm{~b}$ also shows the relation between the area product of the transformer used to couple the DC links and $L_{d c}$ Original and the sum of the area product of the magnetic devices in the proposal. 
The reduction of the total area product is below 0.5 p.u. of the $L_{d c}$ Original for $n_{C}=1$ to $n_{C}=5$. This means not only a reduction in the DC inductor value required for the proposal but also a reduction of half of the magnetic energy required in each DC link compared to the original CHB-CSI topology. Figure 4c shows the relation of volume, weight, and footprint between the proposed topology ( $L_{d c}$ Reduced and the magnetic coupling) compared to the use of the $L_{d c}$ Original. The use of magnetically coupled cells allows reducing near $30 \%$ of the required volume and weight of the DC link magnetic devices compared to the original DC inductor, while the footprint is similar. Since the described relations are mainly a function of the load power and power converter switching strategy, this reduction could vary for other cases.

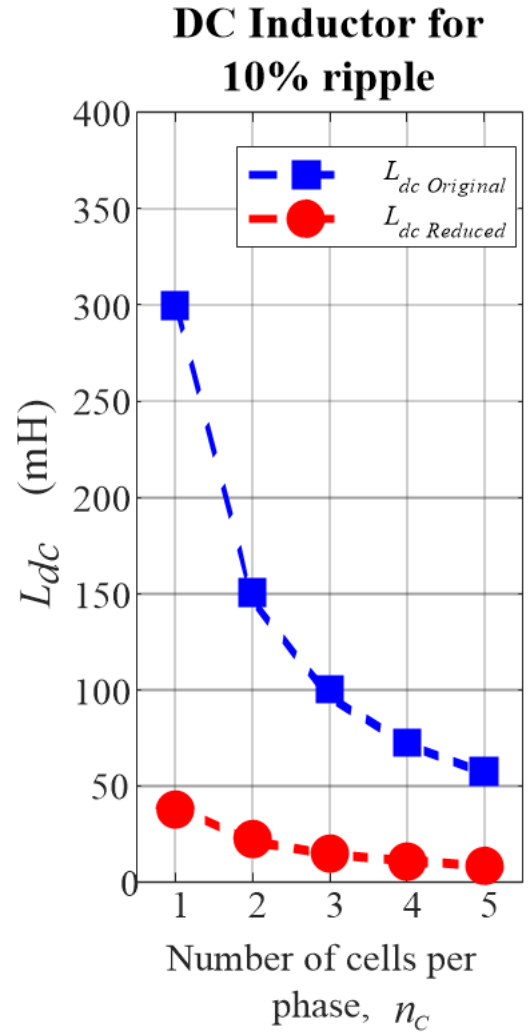

(a)

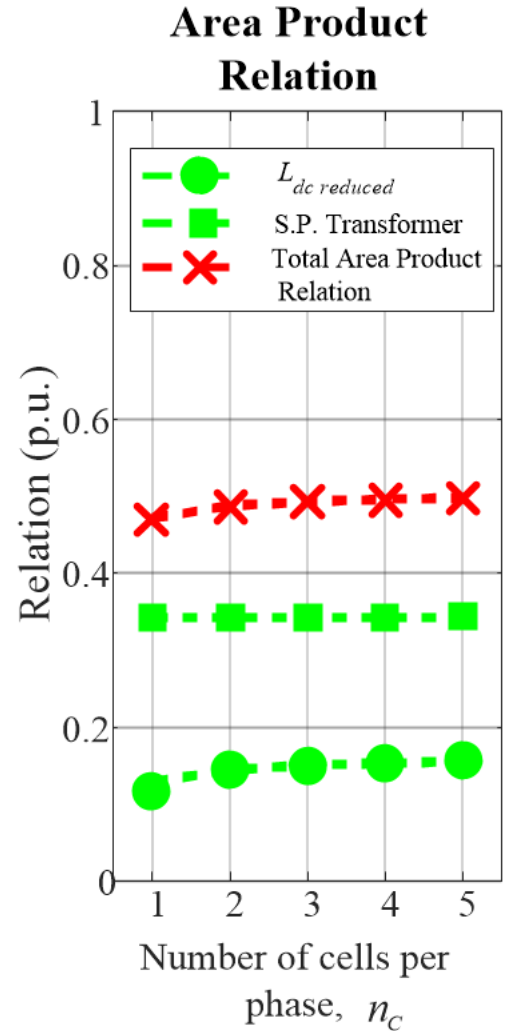

(b)

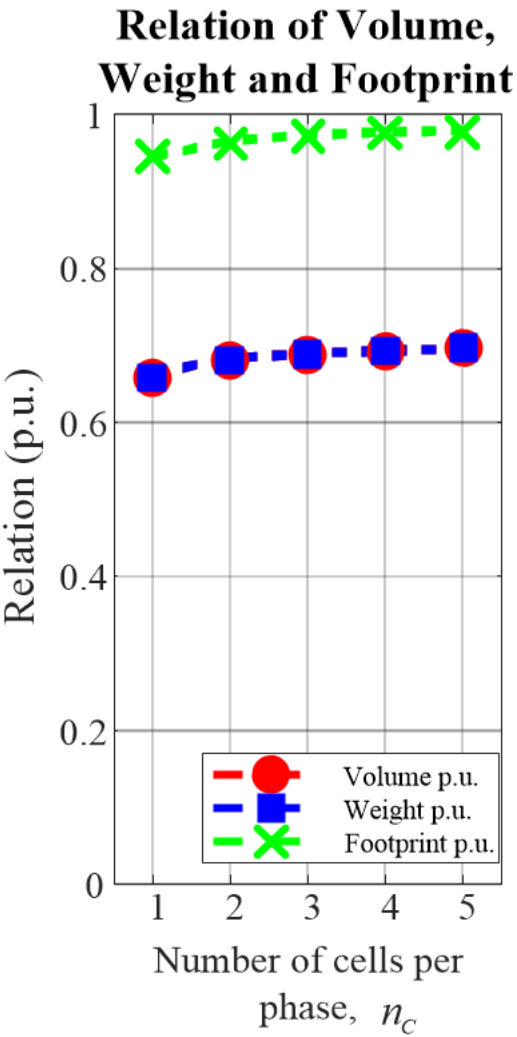

(c)

Figure 4. DC inductor values and area product relation comparison as a function of the number of cells per phase, $n_{C}$; (a) original DC inductor value and reduced DC inductor value for $10 \%$ ripple; (b) area product relation for reduced DC inductor, coupling transformers, and their sum (see Table 1); (c) volume, weight, and footprint relation (see Table 1).

\subsection{Performance of DC Current Controller}

The DC currents controllers' performance is tested using a 20\% step change for both cases, $n_{C}=1$ and $n_{C}=2$. Figure 5 a shows the dynamics of all DC currents for $n_{C}=1$ and $n_{C}=2$. In both cases, the DC currents in the coupled cells are equalized thanks to the dedicated control scheme in each cell, which controls the cell input current in a decoupled way (Figure 5b).

After the reference change, the load voltage increases its value by $20 \%$ (Figure $5 \mathrm{c}$ ) while maintaining the output voltage quality. For the case of $n_{C}=2$, the cell output voltage in each cascaded cell is half the load voltage, and their distortion is higher than the load voltage. This is due to the multilevel modulation strategy used in the inverter stage, which allows the compensation of switching harmonics among cells, while the series connection enables the division of the load voltage in several cells. Thanks to the control and equalization of the DC currents, the behavior of the cell output voltage is similar in both cells. 
One cell per phase case $\left(n_{C}=1\right), 10 \%$ dc current ripple for $f_{i}=50 \mathrm{~Hz}$
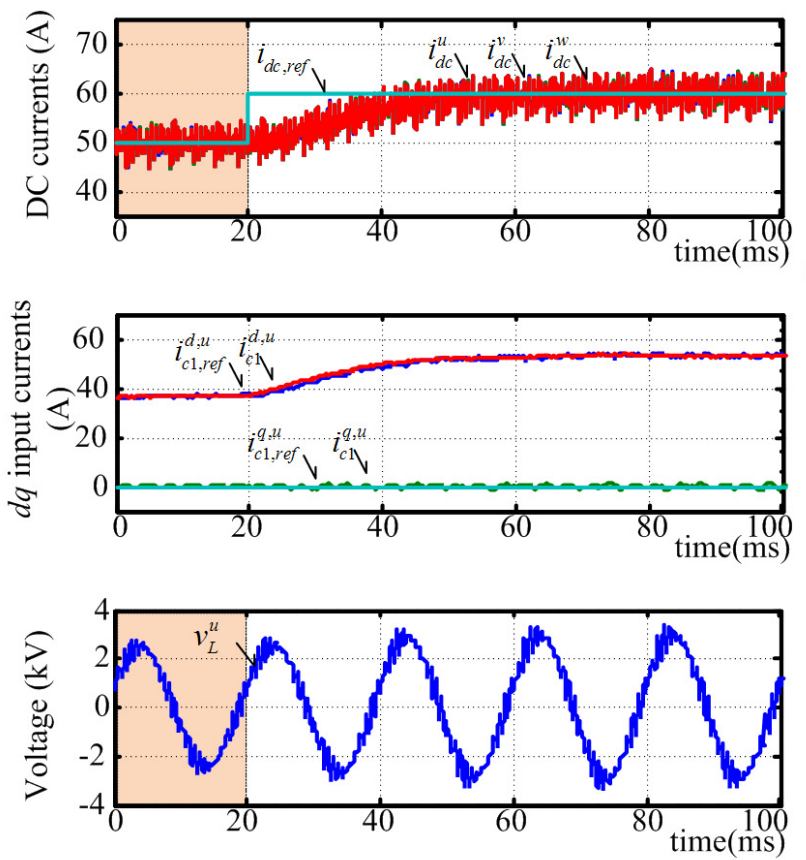

Two cells per phase case $\left(n_{C}=2\right), 10 \%$ dc current ripple for $f_{i}=50 \mathrm{~Hz}$

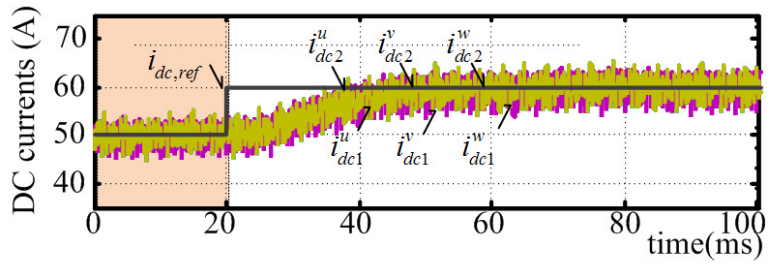

(a)

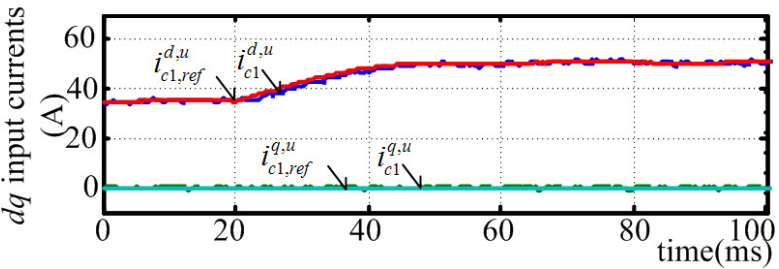

(b)

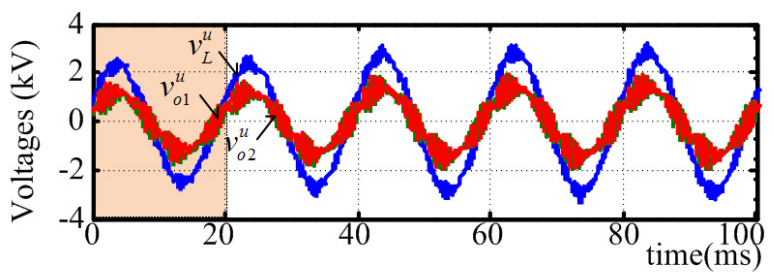

(c)

Figure 5. DC controller performance for 20\% reference step change: (a) DC current; (b) $d q$ input currents and their references; (c) output voltage and load voltage.

\subsection{Performance under Frequency Changes}

Using the same consideration of Section 6.2, the performance of the proposal under inverter frequency step changes is shown in Figure 6, for $n_{C}=1$ and $n_{C}=2$. Step changes are set in $10 \mathrm{~Hz}$ every $100 \mathrm{~ms}$ from $30 \mathrm{~Hz}$ at $t=0 \mathrm{~ms}$ up to $70 \mathrm{~Hz}$ at $t=400 \mathrm{~ms}$, while the switching frequency is set at 10 times the inverter frequency, and the DC current reference is set at $50 \mathrm{~A}$. The load voltage is shown in Figure 6a, where a low distortion can be noticed. The load voltage level and the cell input current (Figure 6c) increase in every frequency change because the DC current level is regulated at $50 \mathrm{~A}$ (Figure 6b), and the impedance is a function of the frequency. In addition, there is no oscillation in the DC current thanks to the oscillating power compensation.

\subsection{Steady-State Performance}

To show the steady-state performance of the proposal, the spectrum is computed for both $n_{C}=1$ and $n_{C}=2$, with the inverter frequency equal to $50 \mathrm{~Hz}$, and a DC current of $50 \mathrm{~A}$ (using the waveforms highlighted in orange in Figures 5 and 6). Figure 7a shows the DC current spectrum, where no 2 nd harmonic is observed and relevant harmonics are present at the inverter carrier frequency ( 24 p.u.) with a similar amplitude in both cases. The above corroborates the oscillating power compensation achieved by the proposal. As for the load voltage (Figure $7 \mathrm{~b}$ ), the $n_{C}=1$ case has a bigger THD (THD $=11.9 \%$ ) than $n_{C}=2$ case $(\mathrm{THD}=5.8 \%)$ due to the use of a multilevel modulation strategy set in the inverter stage, which allows compensating the voltage harmonic near the inverter switching frequency for $n_{C}=2$. In this case, no $3 \mathrm{rd}$ harmonic is presented because there is no 2 nd harmonic on the DC current.

Finally, in the cell input current (Figure 7c), only the fundamental component is observed because the SPWM carrier is set to a frequency of 33 p.u., and the LC resonance frequency is $195 \mathrm{~Hz}$. This was intentionally designed to decouple the rectifier and inverter analysis. 
One cell per phase case $\left(n_{C}=1\right), 10 \%$ dc current ripple for $f_{i}=50 \mathrm{~Hz}$
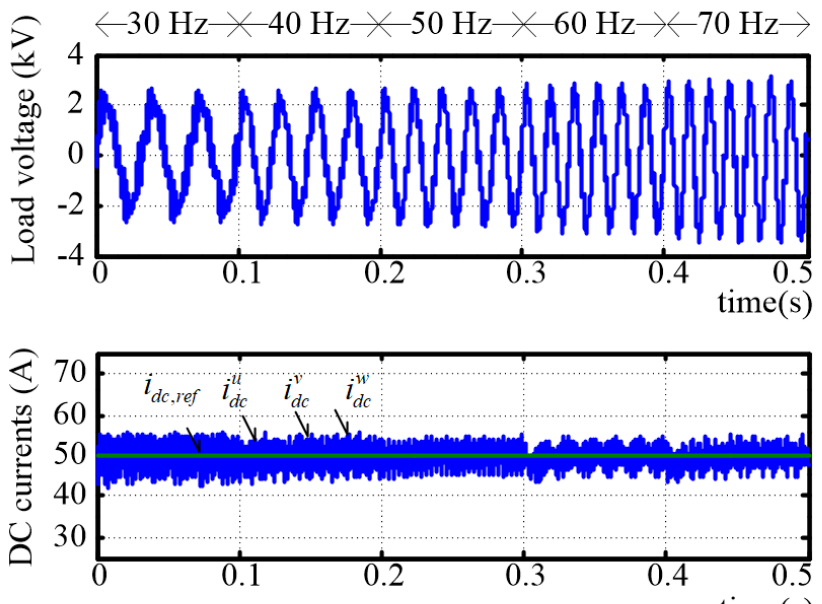

time(s)

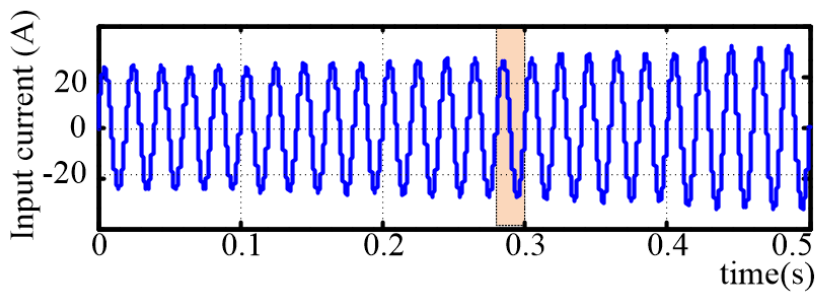

Two cells per phase case $\left(n_{C}=2\right), 10 \%$ dc current ripple for $f_{i}=50 \mathrm{~Hz}$

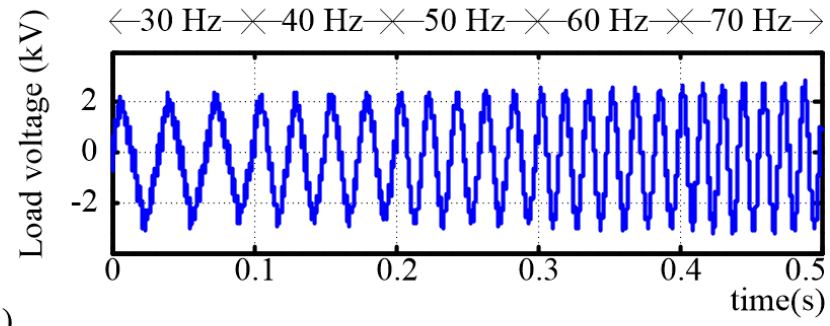

(a)

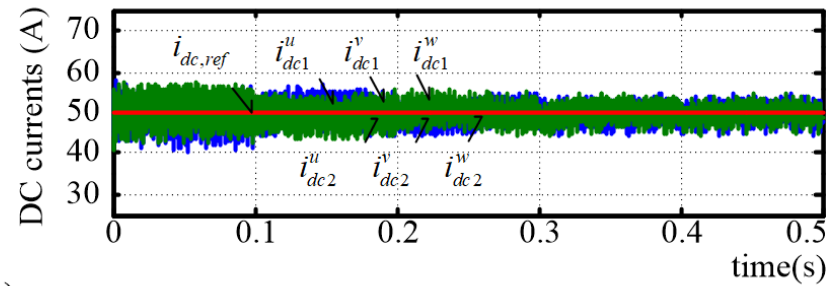

(b)

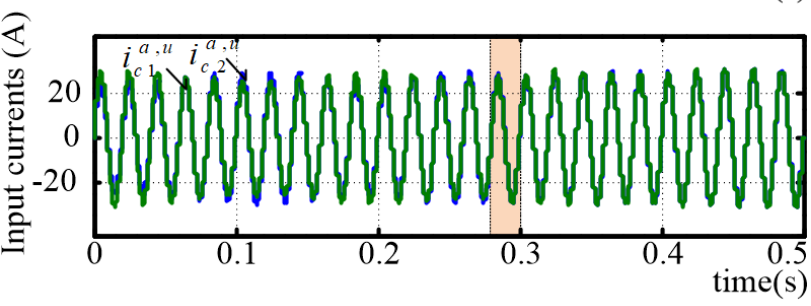

Figure 6. Performance under inverter frequency changes: (a) load voltage; (b) DC currents in each cell; (c) cell input current.
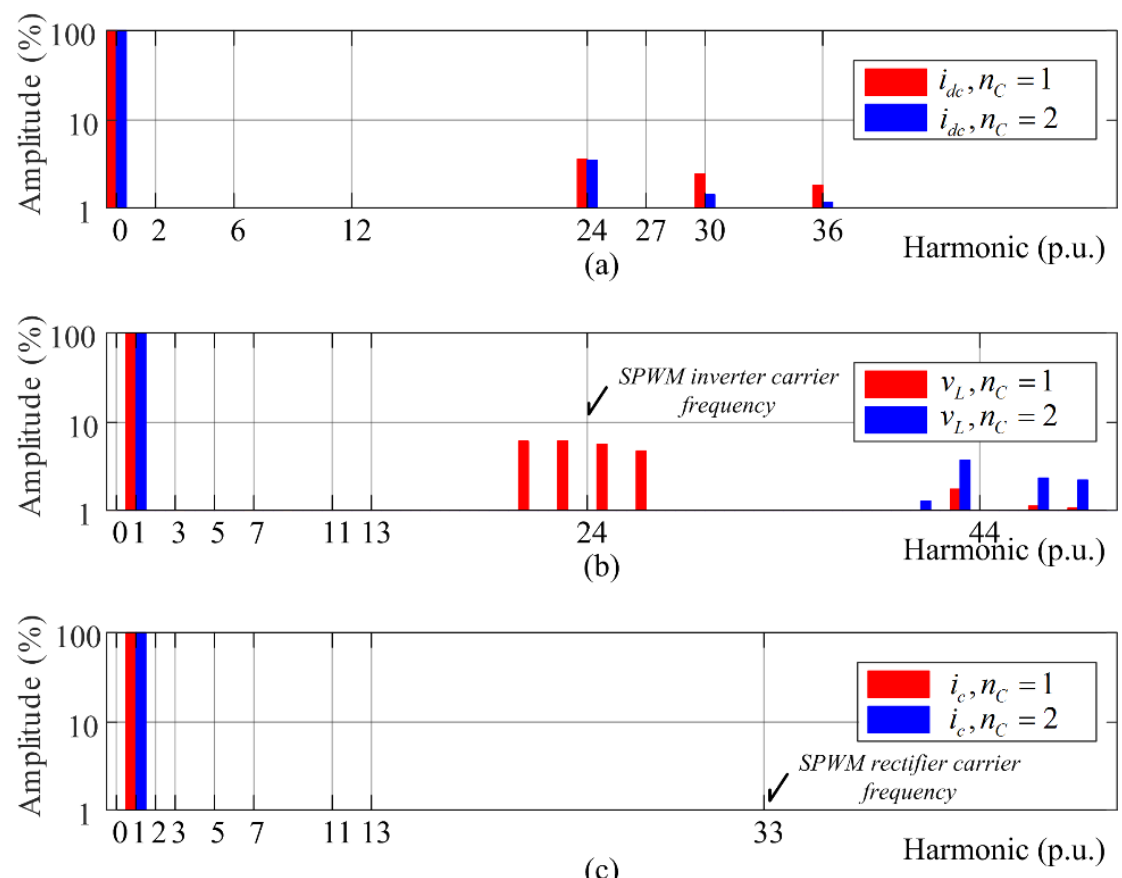

Figure 7. Spectra for steady state, per unit (p.u.) with respect to $f_{i}=50 \mathrm{~Hz}, I_{d c}=50 \mathrm{~A}$ (using waveforms shown in Figures 5 and 6, and highlighted with orange); (a) dc current for $n_{C}=1$ (THD $=5 \%$ ) and $n_{C}=2(\mathrm{THD}=4.3 \%)$ (see Figure 5a); (b) load voltage current for $n_{C}=1(\mathrm{THD}=11.9 \%)$ and $n_{C}=2$ $(\mathrm{THD}=5.8 \%)$ (see Figure $5 \mathrm{c})$; (c) cell input current for $n_{C}=1(\mathrm{THD}=0 \%)$ and $n_{C}=2(\mathrm{THD}=0 \%)$ (see Figure $6 c$ ). 


\section{Experimental Results}

To test the implementation feasibility of the proposal, a laboratory prototype using three cells magnetically coupled through single-phase transformers was implemented. The control strategy was performed using three TMS320C6713 DSK-each to control one cell in a dedicated way-and ADS8332 EVM boards for signal acquisition. A digital PLL synchronizes the DSPs with the AC mains, while common digital signals command the changes for the DC current references. Parameters of the experimental system for both the power topology and controllers are shown in Table 2. The dynamics of the DC currents are set to meet the dynamic performance of the previously simulated case.

As for the control performance, Figure 8 shows the dynamic response for a DC current step change, while Figure 9 shows the steady-state performance at the end of the step change, and Figure 10 shows the main waveform spectra. Thanks to the control strategy, all the DC currents respond in a similar way to the reference change (Figure 8a) and have a similar level in steady state (Figure 9a), demonstrating that the control strategy equalizes the DC currents and, thereby, enables the oscillating power compensation through the magnetic coupling. After the DC current step up, the inverter output current, the output voltage, and the magnetic coupling voltage increase their values, as shown in Figure $8 \mathrm{~b}$. Consequently, at the input of the cell, the power factor displacement control keeps the current in phase with the cell input voltage, ensuring this condition before, during, and after the DC current step change (Figure 8c).

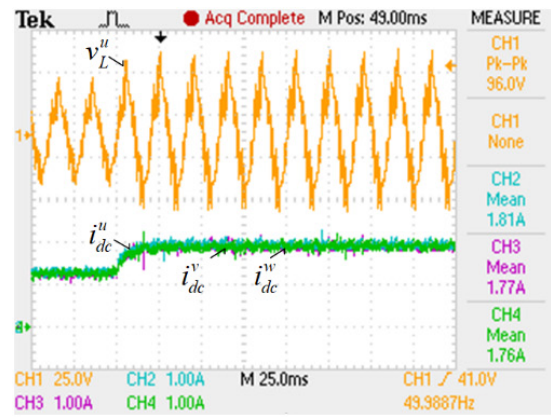

(a)

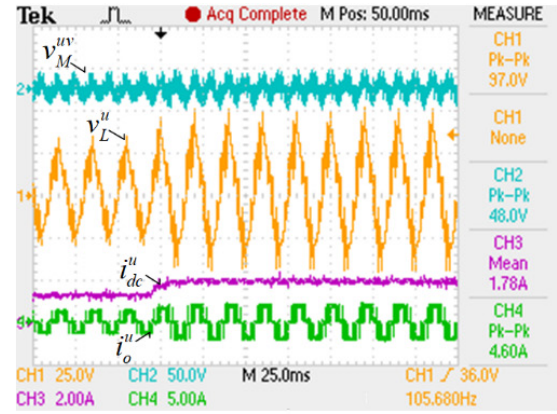

(b)

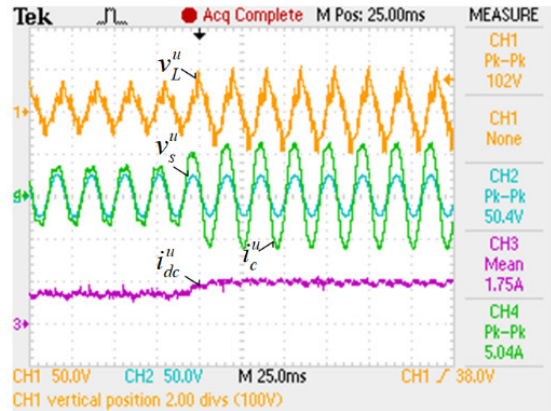

(c)

Figure 8. Performance for DC current change; (a) load voltage $(\mathrm{CH} 1)$, DC currents in each cell $(\mathrm{CH} 2$, $\mathrm{CH} 3$, and $\mathrm{CH} 4)$; (b) load voltage (CH1), magnetic coupling voltage (CH2), DC current (CH3), PWM output current $(\mathrm{CH} 4)$; (c) load voltage $(\mathrm{CH} 1)$, cell input currents and cell input voltage $(\mathrm{CH} 2$ and $\mathrm{CH} 4)$ and DC current (CH3).

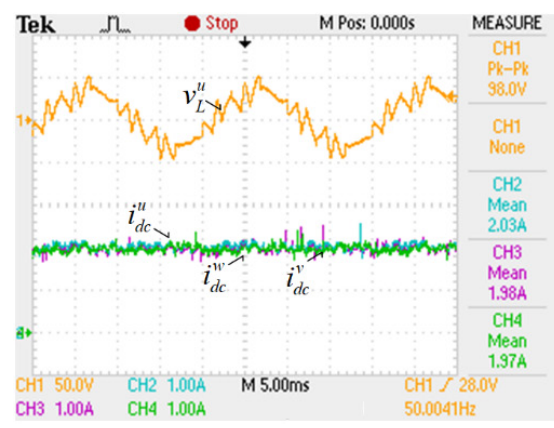

(a)

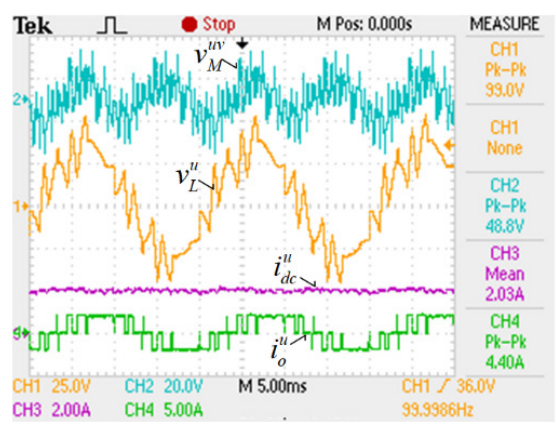

(b)

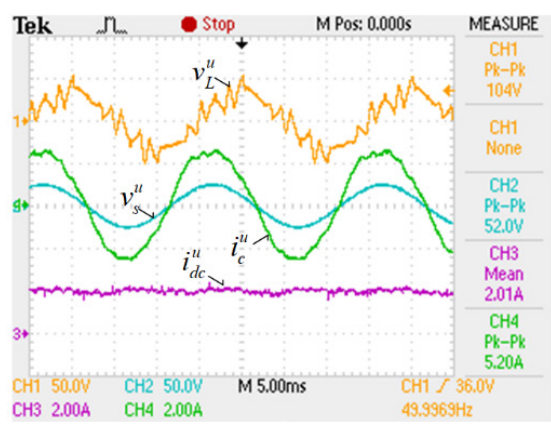

(c)

Figure 9. Performance for steady state: (a) load voltage ( $\mathrm{CH} 1, \mathrm{THD}=30.2 \%)$, DC currents in each cell $(\mathrm{CH} 2, \mathrm{THD}=4.3 \%, \mathrm{CH} 3, \mathrm{THD}=4.1 \%$ and $\mathrm{CH} 4, \mathrm{THD}=4.2 \%) ;(\mathrm{b})$ load voltage $(\mathrm{CH} 1, \mathrm{THD}=30.2 \%)$, magnetic coupling voltage $(\mathrm{CH} 2, \mathrm{THD}=12.4 \%)$, DC current $(\mathrm{CH} 3, \mathrm{THD}=4.1 \%)$, PWM output current $(\mathrm{CH} 4, \mathrm{THD}=46.2 \%)$; (c) load voltage $(\mathrm{CH} 1, \mathrm{THD}=30.2 \%)$, cell input voltage and cell input current $(\mathrm{CH} 2, \mathrm{THD}=2.2 \%$ and $\mathrm{CH} 4, \mathrm{THD}=6.7 \%)$, and DC current $(\mathrm{CH} 3, \mathrm{THD}=4.3 \%)$. 


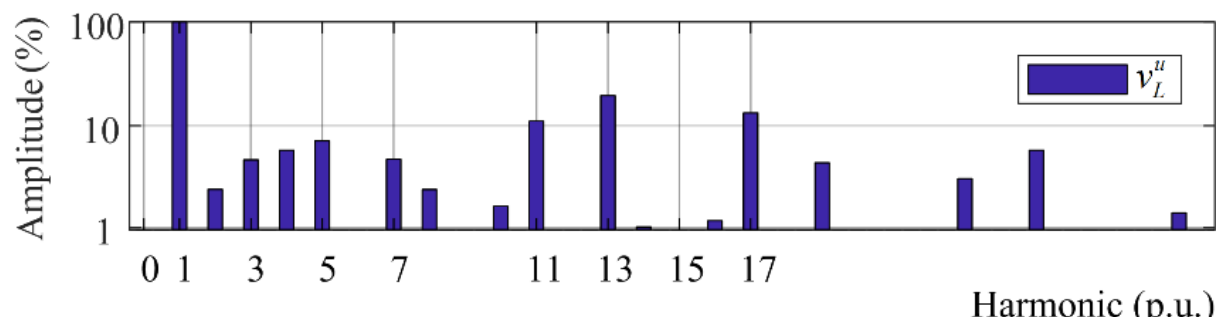

(a)
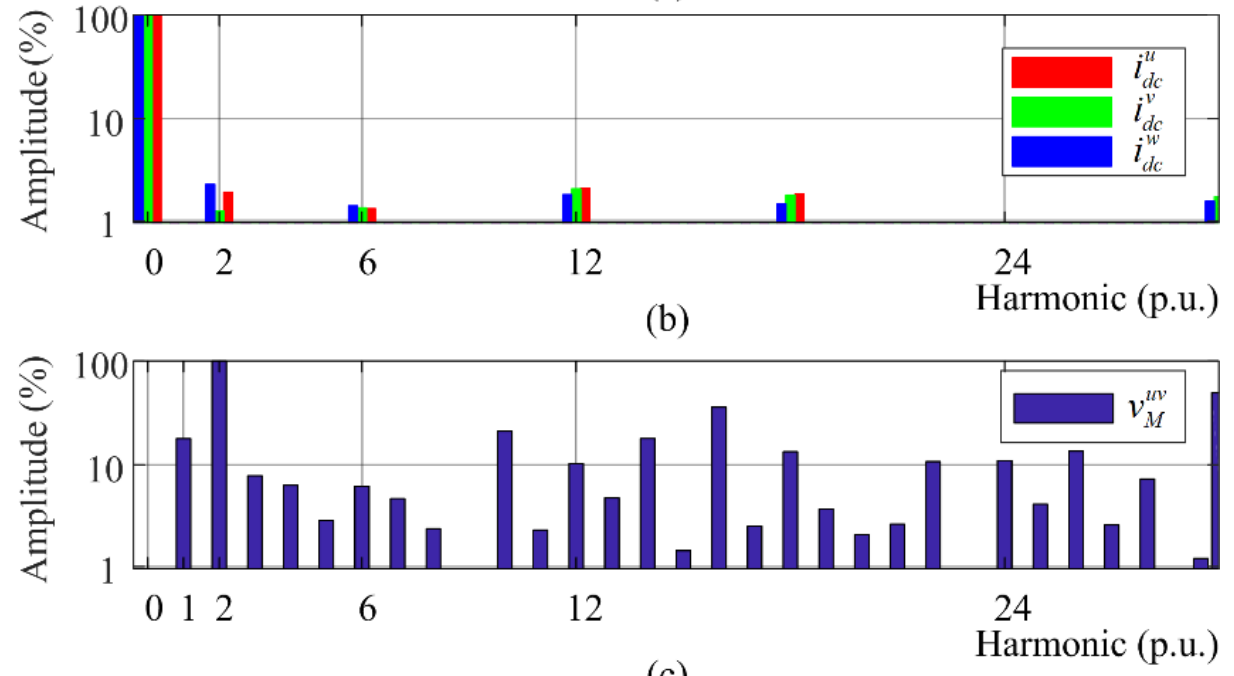

(c)

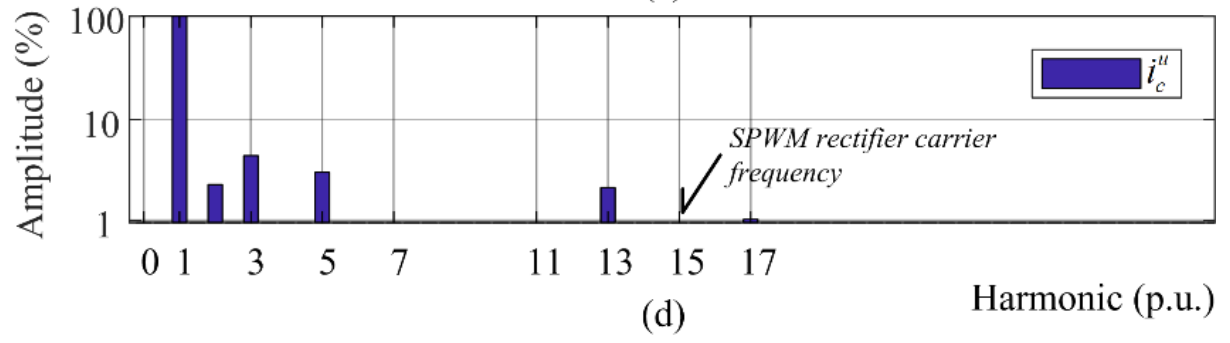

Figure 10. Spectrum of experimental waveform presented in Figure 9, per unit (p.u) with respect to $50 \mathrm{~Hz}$; (a) load voltage; (b) DC currents in each cell; (c) magnetic coupling voltage; (d) cell input current.

About the oscillating power compensation, in steady state, the oscillating power is mostly compensated, and the DC currents have less than $2 \%$ of the 2 nd harmonic in its spectrum, as shown in Figure 10b. According to Section 3, the magnetic coupling allows compensating positive and negative sequences among DC links, and this can be observed in the magnetic coupling voltage (Figure 9b), which has mainly a 2nd harmonic, and Figure 10c where, additionally to the 2nd harmonic, there are other harmonic components caused by the current-source converters commutation.

The effects of the DC current 2nd harmonic at the AC sides are the unwanted harmonics around the 3rd harmonic, which are present with amplitudes lower than $10 \%$ (see Figure 10a for the load voltage and Figure 10d for the cell input currents). The above is due to the second-order system of the capacitive filter, the inductive load, and the resonance of the input LC filter. For the load voltage, THD is equal to $30.2 \%$, which is mainly because of these unwanted harmonics and the use of selective harmonic elimination at the inverter stage, which allows reducing the switching frequency of the inverter but increases the THD. On the other hand, the cell input current THD is equal to $4.3 \%$ due to the use of an SPWM carrier frequency equal to 15 p.u. and the effect of the LC resonance (Figure 9c).

The experimental results corroborate that it is possible to compensate for the oscillating power by magnetic couplings among the DC links and to equalize the DC current in the 
coupled cells. This allows reducing the DC inductor value and achieving a good quality of both load voltage and input currents without detriment of the dynamic performance.

\section{About the Effect of the Magnetic Coupling-Based DC Inductor Reduction in the Operating Region of the CHB-CSI}

8.1. About Ac Components Design

From Figures 1 and 2, it is noticeable that at the AC input side and AC output side, there are the same passive components in each cell, which are an LC filter at the threephase input converter and a $C$ filter at the cell output. The design guidelines are already given by the literature in order to find the parameters of these filters as a function of the mains grid frequency, the switching frequency, and the power of the converter $[15,16,29,32]$. The design of the AC passive components is based on the attenuation of the switching frequency, avoiding possible resonances because of the second-order filter at the cell input, the equivalent second-order system of the capacitive filter, and an inductive load. Specifically, for each AC filter, the considerations are as follow:

- The LC input filter is designed to attenuate rectifier harmonic currents because of commutation. As in both cases, the DC oscillating power is compensated by the DC inductor for the original topology and the magnetic couplings for the proposed topology; the effect of this power cannot be considered in the design guidelines, which are documented in [29,32]. An additional consideration is to set the resonance frequency out of the band, where the effect of the oscillating power can generate an unwanted harmonic.

- The cell output capacitor is set to achieve a desired THD in the load voltage. This capacitor is designed to filter out the current harmonics injected by the single-phase inverter, considering the current load effect. The design guideline is shown in [15], and [16] examines the above as well as the effect of connecting several cells in series, showing the possibility to reduce the capacitor number when $n_{C}$ increases. In addition, the value of the capacitive filter is minimum when the modulation index of the inverter is maximum.

\subsection{Operating Region Effect of the Dc Inductor Reduction}

In [31], the operating regions are computed for different CHB topologies based on three-phase/single-phase current source cells with oscillating power compensation, where the operating region is defined employing the $d q$ model, such as the one presented in (24), (25), and (26). From there, the active power and reactive power for each cell can be computed considering the Park transformation synchronized with the cell input voltage as:

$$
\begin{gathered}
P_{c}=V_{s}^{d} I_{c}^{d}=\frac{K_{d c} M_{r}^{d}}{\left(1-\omega_{s}^{2} / \omega_{L C}^{2}\right)}\left(V_{s}^{d}\right)^{2}, \\
Q_{c}=-V_{s}^{d} I_{c}^{q}=-\left[\frac{K_{d c} M_{r}^{d} M_{r}^{q}}{\left(1-\omega_{s}^{2} / \omega_{L C}^{2}\right)^{2}}+\frac{\omega_{s}^{2} C_{f}}{\left(1-\omega_{s}^{2} / \omega_{L C}^{2}\right)^{2}}\right]\left(V_{s}^{d}\right)^{2},
\end{gathered}
$$

while the load voltage can be computed from

$$
V_{L}\left(\omega_{i}\right)=n_{C} \frac{K_{d c} M_{r}^{d} Z_{m}\left(\omega_{i}\right)}{G_{r}\left(1-\omega_{s}^{2} / \omega_{L C}^{2}\right)} V_{s}^{d},
$$

where $K_{d c}$ is defined as a function of the rectifier modulation gain, the losses in the DC link $\left(R_{d c}\right)$, and the equivalent impedance that the cell feeds, thus,

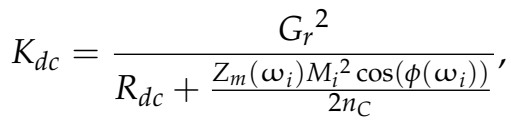


and $Z_{m}\left(\omega_{i}\right)$ is the equivalent parallel impedance of the load and the capacitive filter, and $\phi_{m}$ is the angle of $Z_{m}\left(\omega_{i}\right)$.

From (61) to (64), it is easy to note that the DC inductor value does not affect the topology operating region because it is not in the power expressions or in the load voltage expression; however, its parasitic resistance in $R_{d c}$, shown in (64), will reduce the operating region. On the other hand, the AC components are present in (61) to (63), and they have an influence on the cell operating region and its output voltage; as previously discussed, those components are not a function of the DC inductor value. Then, the use of magnetic coupling on the DC link to compensate for the oscillating power does not modify the operating region of the CHB-CSI topology compared to the original CBH-CSI topology reported in [16], and the $\mathrm{AC}$ components do not require modifications from one case to the other due to the use of the magnetic couplings among the DC links. The above does not include the increases or decreases of the parasite resistance of the DC elements, which is not considered in this analysis and could be reduced when the inductor value is reduced.

\section{Conclusions}

This work studies a reduction strategy for the DC inductors size in a Cascaded HBridge topology based on current-source inverters. The proposed strategy is based on the use of transformers to magnetically couple three cells that feed different phases of the load and a control strategy that equalizes the DC currents in the coupled cells in order to avoid the transformer saturation. This proposal allows compensating the oscillating power among cells and, therefore, designing the DC inductor as a function of the switching frequency instead of a function of the oscillating power. Computational simulation and tests in a laboratory prototype show that it is achievable to reduce the required DC inductor below $20 \%$ of the original topology, which leads to a reduction to near half of the magnetic energy required, and also to a reduction of the weight and volume of each cell, notwithstanding the addition of the transformer to the DC link.

Based on these results, the reduction of the DC inductor value does not affect the dynamic or the steady-state performances of the whole converter, while the effect of the reduction in the other passive components of the CHB-CSI analysis shows that the use of DC links magnetically coupled does not affect the design nor the operating region of the whole topology.

Author Contributions: Conceptualization, P.E.M., C.R.B. and J.R.E.; methodology P.E.M. and J.R.E.; validation, P.E.M., C.R.B., E.E.E. and J.R.E. formal analysis, P.E.M.; investigation, P.E.M. and C.R.B.; writing-original draft preparation, P.E.M. and C.R.B.; writing-review and editing, P.E.M., C.R.B., E.E.E. and J.R.E.; project administration, P.E.M.; funding acquisition, P.E.M. and C.R.B. All authors have read and agreed to the published version of the manuscript.

Funding: This work was supported by the Chilean Government under Research Project ANID/FON DECYT/1201683 and Project ANID/FONDECYT/1201308.

Institutional Review Board Statement: Not applicable.

Informed Consent Statement: Not applicable.

Data Availability Statement: Data are available on request due to privacy restrictions. The data presented in this study are available upon request from the corresponding author.

Acknowledgments: The authors would like to thank the Chilean Government projects ANID/FOND ECYT/1201683, ANID/FONDECYT/1201308, and the technical support of the projects ANID/FOND ECYT/11181203 and FONDAP/SERC/15110019; to the Universidad del Bío-Bío and the support of the projects DIUBB 182510 4/R and GI-160510EF; to Macrofacultad de Ingeniería UFRO-UBB-UTAL, Chile, 14ENI2-26866.

Conflicts of Interest: The authors declare no conflict of interest. 


\section{Nomenclature}

$\begin{array}{ll}n_{C} & \text { Number of cells per phase } \\ \mathbf{v}_{\mathbf{s}} & \text { Cell voltage supply } \\ \mathbf{i}_{\mathbf{c}} & \text { Cell input current } \\ \mathbf{v}_{\mathbf{T}} & \text { Topology voltage supply } \\ \mathbf{i}_{\mathbf{T}} & \text { Topology input current } \\ \mathbf{v}_{\mathbf{o}} & \text { Cell output voltage } \\ \mathbf{v}_{\mathbf{l}} & \text { Load voltage } \\ \mathbf{i}_{\mathbf{L}} & \text { Load current } \\ \mathbf{s}_{\mathbf{r}} & \text { Modulating vector (rectifier) } \\ s_{i} & \text { Modulating signal (inverter) } \\ i_{d c} & \text { DC link current } \\ n_{C} & \text { Number of cells in a series array } \\ a b c & \text { Stationary coordinates for three-phase input } \\ u v w & \text { Stationary coordinates for three-phase output } \\ d q & \text { Rotating coordinates }\end{array}$

\section{References}

1. Rodriguez, J.; Bernet, S.; Bin, W.; Pontt, J.O.; Kouro, S. Multilevel Voltage-Source-Converter Topologies for Industrial MediumVoltage Drives. IEEE Trans. Ind. Electron. 2007, 54, 2930-2945. [CrossRef]

2. Franquelo, L.G.; Rodriguez, J.; Leon, J.I.; Kouro, S.; Portillo, R.M.A.M.; Prats, M.A. The age of multilevel converters arrives. IEEE Ind. Electron. Mag. 2008, 2, 28-39. [CrossRef]

3. Malinowski, M.; Gopakumar, K.; Rodriguez, J.; Pérez, M.A. A Survey on Cascaded Multilevel Inverters. IEEE Trans. Ind. Electron. 2009, 57, 2197-2206. [CrossRef]

4. Song, Y.; Wang, B. Survey on Reliability of Power Electronic Systems. IEEE Trans. Power Electron. 2013, 28, 591-604. [CrossRef]

5. Peng, H.; Hagiwara, M.; Akagi, H. Modeling and Analysis of Switching-Ripple Voltage on the DC Link Between a Diode Rectifier and a Modular Multilevel Cascade Inverter (MMCI). IEEE Trans. Power Electron. 2012, 28, 75-84. [CrossRef]

6. Sun, L.; Zhenxing, W.; Weiming, M.; Xiao, F.; Cai, X.; Zhou, L. Analysis of the DC-Link Capacitor Current of Power Cells in Cascaded H-Bridge Inverters for High-Voltage Drives. IEEE Trans. Power Electron. 2014, 29, 6281-6292. [CrossRef]

7. Joseph, A.; Chelliah, T.R. A Review of Power Electronic Converters for Variable Speed Pumped Storage Plants: Configurations, Operational Challenges and Future Scopes. IEEE J. Emerg. Sel. Top. Power Electron. 2018, 6, 103-119. [CrossRef]

8. Wu, B.; Narimani, M. High-Power Converters and AC Drives; John Wiley \& Sons, Ltd.: New York, NY, USA, 2017.

9. Jung, J.J.; Lee, J.H.; Sul, S.K.; Son, G.T.; Chung, Y.H. DC Capacitor Voltage Balancing Control for Delta-Connected Cascaded HBridge STATCOM Considering Unbalanced Grid and Load Conditions. IEEE Trans. Power Electron. 2018, 33, 4726-4735. [CrossRef]

10. Koyama, Y.; Nakazawa, Y.; Mochikawa, H.; Kuzumaki, A.; Sano, K.; Okada, N. A Transformerless 6.6-kV STATCOM based on Hybrid Cascade Multilevel Converter using SiC Devices. IEEE Trans. Power Electron. 2018, 33, 7411-7423. [CrossRef]

11. Townsend, C.D.; Yu, Y.; Konstantinou, G.; Agelidis, V.G. Cascaded H-Bridge Multilevel PV Topology for Alleviation of Per-Phase Power Imbalances and Reduction of Second Harmonic Voltage Ripple. IEEE Trans. Power Electron. 2015, 31, 5574-5586. [CrossRef]

12. Shuvo, S.; Hossain, E.; Islam, T.; Akib, A.; Padmanaban, S.; Khan, M.Z.R. Design and Hardware Implementation Considerations of Modified Multilevel Cascaded H-Bridge Inverter for Photovoltaic System. IEEE Access 2019, 7, 16504-16524. [CrossRef]

13. Coppola, M.; di Napoli, F.; Guerriero, P.; Iannuzzi, D.; Daliento, S.; del Pizzo, A. An FPGA-Based Advanced Control Strategy of a Grid Tied PV CHB Inverter. IEEE Trans. Power Electron. 2015, 31, 806-816. [CrossRef]

14. Baier, C.R.; Melin, P.E.; Guzman, J.I.; Rivera, M.; Muñoz, J.A.; Rothen, J.; Espinoza, J. Current-source cascaded multilevel converters based on single-phase power cells. In Proceedings of the IECON 2013-39th Annual Conference of the IEEE Industrial Electronics Society, Wien, Austria, 10-13 November 2013; pp. 6207-6212.

15. Melin, P.; Espinoza, J.; Guzman, J.; Rivera, M.; Espinosa, E.; Rothen, J. Analysis and design of a Cascaded H-Bridge topology based on current-source inverters. In Proceedings of the IECON 2013-39th Annual Conference of the IEEE Industrial Electronics Society, Wien, Austria, 10-13 November 2013; pp. 6189-6194.

16. Melin, P.E.; Rohten, J.A.; Espinoza, J.R.; Baier, C.R.; Espinosa, E.E.; Munoz, J.A.; Riedemann, J. Analysis and Design of a Multicell Topology Based on Three-Phase/Single-Phase Current-Source Cells. IEEE Trans. Power Electron. 2015, 31, 6122-6133. [CrossRef]

17. Li, Y.W.; Pande, M.; Zargari, N.R.; Wu, B. An input power factor control strategy for high-power current-source induction motor drive with active front-end. IEEE Trans. Power Electron. 2009, 25, 352-359. [CrossRef]

18. Zhang, L.; Ruan, X.; Ren, X. Second-Harmonic Current Reduction for Two-Stage Inverter with Boost-Derived Front-End Converter: Control Schemes and Design Considerations. IEEE Trans. Power Electron. 2018, 33, 6361-6378. [CrossRef]

19. Sun, Y.; Liu, Y.; Su, M.; Xiong, W.; Yang, J. Review of Active Power Decoupling Topologies in Single-Phase Systems. IEEE Trans. Power Electron. 2015, 31, 1. [CrossRef]

20. Irfan, M.S.; Ahmed, A.; Park, J. Power-Decoupling of a Multiport Isolated Converter for an Electrolytic-Capacitorless Multilevel Inverter. IEEE Trans. Power Electron. 2018, 33, 6656-6671. [CrossRef] 
21. Sun, Y.; Liu, Y.; Su, M.; Li, X.; Yang, J. Active Power Decoupling Method for Single-Phase Current-Source Rectifier with No Additional Active Switches. IEEE Trans. Power Electron. 2016, 31, 5644-5654. [CrossRef]

22. Melin, P.E.; Baier, C.R.; Espinoza, J.R.; Munoz, J.A.; Ramirez, R.R.; Maurelia, E.A. On the DC inductors size reduction in a multi-cell topology based on current source converters by means of magnetic couplings. In Proceedings of the IECON 2013-39th Annual Conference of the IEEE Industrial Electronics Society, Wien, Austria, 10-13 November 2013; pp. 6275-6280.

23. Melin, P.E.; Espinoza, J.R.; Baier, C.R.; Rohten, J.A.; Ramirez, R.O.; Moran, L.A. Improved control scheme towards reduced DC link inductors in a Multi-Cell Topology based on Current Source Converters. In Proceedings of the IECON 2012-38th Annual Conference on IEEE Industrial Electronics Society, Montreal, QC, Canada, 25-28 October 2012; pp. $488-493$.

24. Baier, C.R.; Espinoza, J.R.; Melin, P.E.; Espinosa, E.; Munoz, J. A novel multi-level CSI based topology with inter-cell magnetic couplings for minimum DC storage components. In Proceedings of the 2010 IEEE International Symposium on Industrial Electronics, Bari, Italy, 4-7 July 2010; pp. 3193-3198.

25. Baier, C.R.; Espinoza, J.R.; Rivera, M.; Munoz, J.A.; Bin, W.; Melin, P.E.; Yaramasu, V. Improving Power Quality in Cascade Multilevel Converters Based on Single-Phase Nonregenerative Power Cells. IEEE Trans. Ind. Electron. 2014, 61, 4498-4509. [CrossRef]

26. Baier, C.R.; Melin, P.E.; Espinoza, J.R.; Munoz, J.; Guzman, J.I. A novel multi-level topology based on current source power cells for high performance applications. In Proceedings of the 2010 IEEE International Conference on Industrial Technology, Vina del Mar, Chile, 14-17 March 2010; pp. 1333-1338.

27. Espinoza, J.R.; Joos, G.; Moran, L. Decoupled control of the active and reactive power in three-phase PWM rectifiers based on non-linear control strategies. In Proceedings of the 30th Annual IEEE Power Electronics Specialists Conference. Record. (Cat. No.99CH36321), Harleston, SC, USA, 1 July 1999.

28. Smith, C.A.; Corripio, A.B. Principles and Practice of Automatic Process Control, 2th ed.; Wiley: New York, NY, USA, 2006.

29. Filsecker, F.; Álvarez, R.; Bernet, S. Design and losses of PWM current source converters. In Proceedings of the 2010 IEEE International Conference on Industrial Technology, Vina del Mar, Chile, 14-17 March 2010; pp. 737-744.

30. McLyman, C.W.T. Transformer and Inductor Design Handbook, 3rd ed.; CRC Press: Boca Raton, FL, USA, 2004.

31. Melín, P.E.; Espinoza, J.R.; Rohten, J.A.; Espinosa, E.E.; Baier, C.R.; Guzman, J.I. Cascaded H-Bridge topologies comparison for multi-cell current-source inverters under different DC inductor size reduction methods. In Proceedings of the IECON 2014-40th Annual Conference of the IEEE Industrial Electronics Society, Dallas, TX, USA, 29 October-1 November 2014; pp. 4568-4574.

32. Zargari, N.R.; Joos, G.; Ziogas, P.D. Input Filter Design for PWM Current-Source Rectifiers. IEEE Trans. Ind. Appl. 1994, 30, 1573. [CrossRef] 